\title{
A Review on the Enhancement of Mechanical and Tribological Properties of MCrAlY Coatings Reinforced by Dispersed Micro- and Nano-Particles
}

\author{
Ali Zakeri ${ }^{1}$, Elnaz Bahmani ${ }^{2}$ and Ali Ramazani ${ }^{3, *}$ \\ 1 Department of Materials Science and Engineering, McMaster University, Hamilton, Ontario L8S 4L7, Can- \\ ada; zakera1@mcmaster.ca \\ 2 Department of Materials Engineering, Tarbiat Modares University, P.O.Box: 14115-143, Tehran, Iran; bah- \\ manielnaz@modares.ac.ir \\ * Correspondence: of Mechanical Engineering, Massachusetts Institute of Technology, Cambridge, MA 02139, USA; \\ Correspondence: ramazani@mit.edu
}

\begin{abstract}
The application of metal-matrix composite coatings for protecting and improving the service life of sliding components has demonstrated to have the potentials of meeting the requirements of a diverse range of engineering industries. Recently, a significant body of research has been devoted to study the mechanical and tribological performance of dispersion-strengthened MCrAlY coatings. These coatings belong to a class of emerging wear-resistant materials, offering improved properties and being considered as promising candidates for the protection of engineering structural materials exposed to tribological damage, especially at elevated temperature regimes. This paper attempts to comprehensively review the different reinforcements used in the processing of MCrAlY-based alloys and how they influence the mechanical and tribological properties of the corresponding coatings. Further, the major fabrication techniques together with their benefits and challenges are also reviewed. Discussion on the failure mechanisms of these coatings as well as the main determining factors are also included. In addition, a comprehensive survey of studies and investigations in recent times are summarized and elaborated to further substantiate the review.
\end{abstract}

Keywords: Metal matrix composites; MCrAlY; Mechanical properties; Tribological properties; Wear; Erosion

\section{Introduction}

It is self-evident that the design and manufacturing strategy of the specified materials are governed by their appropriate properties for the intended industrial applications. That being said, any operating material will interact with its environment during service, by which it can pose technical problems and, as a consequence, limit its lifetime. Irrespective of the nature of this interaction (mechanical or chemical), it takes place at the surface. In order to prevent or limit these undesirable interactions, an efficacious strategy is to deposit a coating with the tailored capabilities [1]. Coatings are highly beneficial in conditions involving wear, corrosion or the combined effects of these detrimental phenomena. A broad spectrum of different materials can be used as a coating and a wide array of deposition technologies are available. Covering these issues is beyond the scope of this paper, which will concern with the dispersion-strengthened MCrAlY-based coatings developed for the tribological applications in demanding environments.

It goes without saying that there has been extensive research on the improvement of oxidation resistance of MCrAlY ( $\mathrm{M}=\mathrm{Ni}$ and/or $\mathrm{Co}$ ) coatings. These types of coatings provide and maintain satisfactory level of corrosion and oxidation resistance, when they are applied and used in the hot-section components of gas turbines. These components are mostly made of superalloys and the high-temperature corrosion protection is commonly provided by thermal barrier coating (TBC) systems. Conventional TBCs consist of a 
duplex structure comprised of an oxidation-resistant MCrAlY bond coat and a thermal insulating ceramic top coat (mainly yttria stabilized zirconia, YSZ). Application of TBCs enables the use of superalloys and prevent their overheating in areas such as first-stage blades and vanes, where the gas temperatures are close or above the service temperature of these materials $\left(\mathrm{T}>1000{ }^{\circ} \mathrm{C}\right)$ [2].

In sections such as second stages of a gas turbine engine and compressor blades, which experience temperatures lower than $750{ }^{\circ} \mathrm{C}$, an overlay coating can be used without the need for the ceramic top coat [3]. Both tribological and corrosion properties are important for the materials used as overlay coatings in these areas. The tribological damage phenomena can occur in both aero and land-based gas turbines which oftentimes results from the impact of foreign objects such as sand particles, volcanic fly ashes, ice or salt crystals, or delaminated parts of TBCs. Other complex issues, including fretting wear and fretting fatigue may also arise [4]. The presence of these particles originates from inefficient or incomplete filtration of the air entering the compressor or the combustion chamber [5]. These damages induce a change in geometry of the components, which has a direct effect on the compressor aerodynamics and reduction in performance. Moreover, increased drag and surface crack formation can occur due to the surface roughening effects of tribological damages [6]. In order to combat these life-limiting phenomena, several protective coatings have been proposed to be deposited on the structural materials experiencing sliding contacts. Figure 1 shows the five main characteristics expected from a coating to be considered fit for the high-temperature tribological applications. It should be noted that achieving a combination of these characteristics could be challenging and even mutually exclusive.

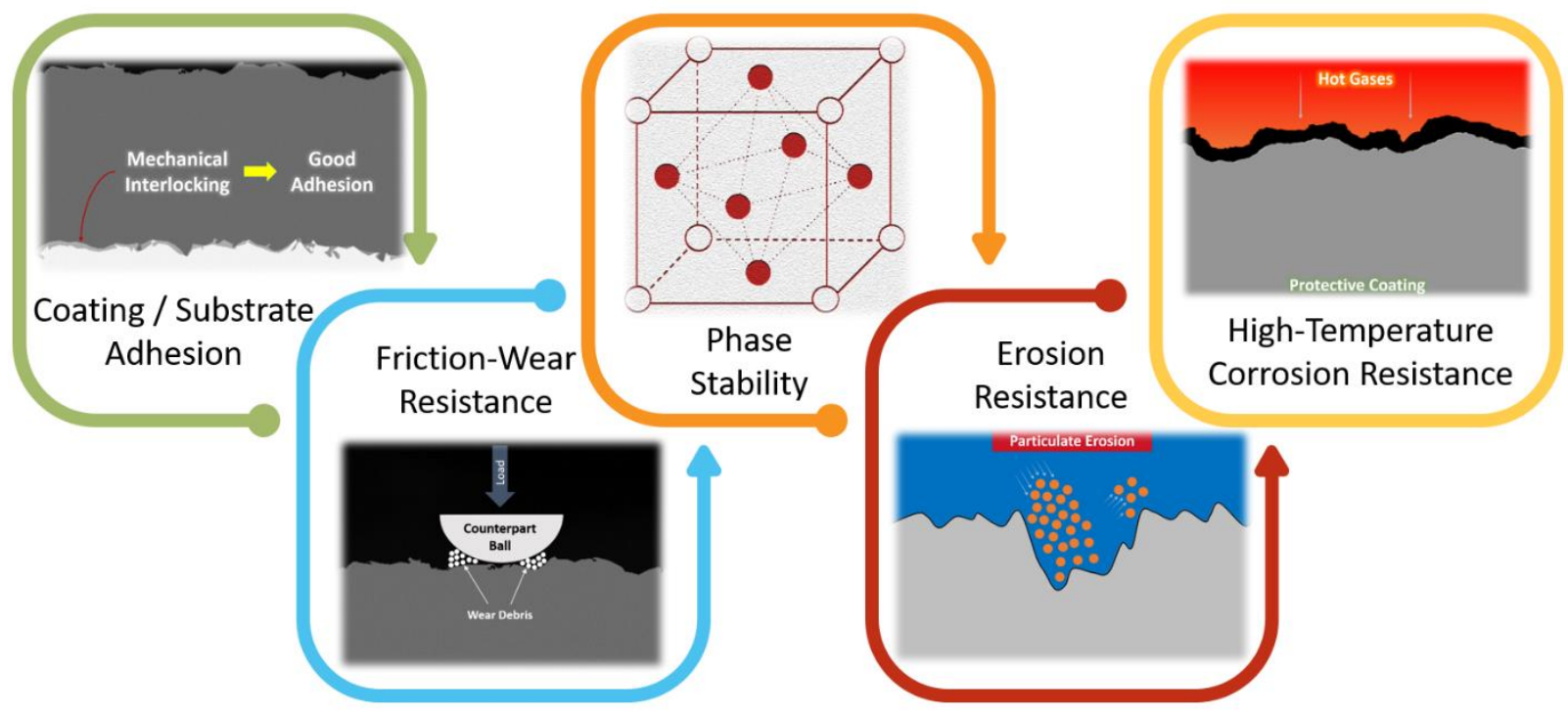

Figure 1. Schematic representing the main five characteristics of coatings required for the high-temperature tribological applications.

Plasma spraying of special powders with $\mathrm{NiCr}$ or NiMoAl matrices along with hard phases have exhibited good tribological performances. The background of the development of these coatings is based on the experimental studies of NASA, which has resulted in the application of solid lubricant coatings [7]. In fact, efforts were made to overcome the limitations of liquid lubricants, where the upper limit is approximately $300{ }^{\circ} \mathrm{C}$ due to oxidation, and also to extend capabilities of solid lubricants into higher temperatures without losing the effectiveness. At present, the state-of-the-art family of high-temperature solid lubricant materials includes patented powder blends, designated as PS304 $\left(\mathrm{NiCr}-\mathrm{Cr}_{2} \mathrm{O}_{3}-\mathrm{Ag}-\mathrm{BaF}_{2} / \mathrm{CaF}_{2}\right)$ and $\mathrm{PS} 400$ (NiMoAl- $\left.\mathrm{Cr}_{2} \mathrm{O}_{3}-\mathrm{Ag}-\mathrm{BaF}_{2} / \mathrm{CaF}_{2}\right)$. Plasma-sprayed composite coatings of these powders have shown effective lubrication, better tribological performance, and improved adhesion [8]. That being said, the aforementioned coatings 
face some shortcomings such as dimensional instability, low oxidation and hot corrosion resistance when being used in higher temperature regimes (especially above $\approx 750{ }^{\circ} \mathrm{C}$ ) [9].

Another approach taken to effectively mitigate the wear phenomenon is to employ WC-based coatings. The experiments of these coatings under hostile conditions have confirmed their effectiveness, which is due to their high hardness and favorable wear resistance even at high temperature regimes [10][11]. The thermal spraying techniques such as atmospheric plasma spray (APS) and high-velocity oxy-fuel (HVOF) stand out as the most commonly preferred processes for industrial applications of these coatings [12][13][14][15]. That being said, pure carbide powders suffer from decarburization, oxidation, and thermal decomposition at high temperatures; therefore, they cannot be directly injected into the thermal jets. In light of this fact, ductile and easily melted binder materials such as $\mathrm{Ni}, \mathrm{Co}, \mathrm{Cr}$ and their alloys are utilized to embed carbide particles and increase the toughness. This class of coatings, which are usually known as cermets, involves a large number of compositions such as WC-Co, WC-Co-Cr and WC-NiCr [4][16]. The compositions of the commercially available feedstock materials indicate that $\mathrm{Co}$ is the predominant binder metal; however, compositions with $\mathrm{Ni}$ are also commercially available, e.g., WC-12Ni and WC-17Ni [17]. Besides, the wettability of WC in Co, as the metal binder, is superior than it is in $\mathrm{Ni}$ [18].

Depending on the synthesis route, the microstructures of the end-product powder can be strikingly different. Generally, the conventional WC-based powders are manufactured through several consecutive steps of mechanical mixing, spray drying and agglomeration, and consolidation heat treatment [19]. In addition, the nanostructured WC-based are attracting great interest as wear-resistant materials. These coatings came into being as a result of academic reports indicating the enhanced wear resistance of sintered nanostructured WC-Co materials. This enhancement is attributed to the carbide grain size refinement which reduces the mean free path of binder phase (Co) and results in low tendency of Co extrusion along with the increased hardness [20]. It should be noted that despite the high effectiveness of cermet coatings in combating the tribological damages at ambient temperature, their performance degrades at elevated temperatures due to the combined impact of mechanical and chemical attack [21]. This can be overcome by using a corrosion-resistant material, as matrix, such as $\mathrm{NiCr}, \mathrm{NiCrSiB}$, and MCrAlY-based alloys. Among the traditional materials used for the binder phase, the family of MCrAlY alloys are relatively new and possess the highest corrosion resistance.

Despite the advantages of MCrAlY alloys, as matrix, in terms of favorable corrosion performance, there still exist some drawbacks like low hardness; thus, pure MCrAlY coatings are not suitable for use on tribological components [22]. Recently, incorporation of hard secondary particles stands out as a viable solution to improve tribological properties of MCrAlY-based composite coatings. In this manner, a coupling synergy between the tough metallic matrix and hard reinforcements would come into effect, by which the hard particles effectively protect the matrix from being shoveled off, as well as resisting against the penetration of tribo-pair; in return, the MCrAlY matrix prevents fracture during sliding [23].

This paper presents an overview of the recent advances and literature specific to the MCrAlY coatings reinforced by dispersed micro- and nano-particles, with particular emphasis on their mechanical and tribological properties. At first, the typical composition of MCrAlY alloys is elucidated, followed by reviewing the different reinforcing materials utilized in the design of dispersion-strengthened MCrAlY-based coatings. Next, the major fabrication techniques and their microstructural features are explored. Finally, the mechanical and tribological behavior of the aforementioned coatings are examined and some concluding thoughts concerning future research and development are proposed. 


\section{Composition and Microstructure of MCrAlY Alloys}

Starting with a FeCrAlY system in the 1960s, a new class of alloy compositions called MCrAlYs came into existence and since then, numerous variations and modifications of these alloys have been experimented by the researchers [24]. A standard MCrAlY alloy contains $\mathrm{Cr}, \mathrm{Al}, \mathrm{Y}$, and either $\mathrm{Ni}, \mathrm{Co}$ or a combination of them. Unlike the traditional diffusion coatings which are highly dependent on the substrate composition [25], these alloys allow good flexibility of design, and their compositions can be tailored for different applications. For instance, it has been reported that the Co-based alloys are more beneficial for the hot corrosion resistance. The Ni-based alloys, on the other hand, have been shown to outperform the other systems in terms of oxidation performance [26][27]. It is noteworthy that the term "MCrAlX" has also been used in some literature, since a diverse range of other minor alloying elements like $\mathrm{Si}, \mathrm{Hf}, \mathrm{Ta}, \mathrm{Pt}$, or Re are also added to the coating composition [28].

The conventional MCrAlY alloys typically contain four elements or more and each element has a specific role. The addition of $\mathrm{Al}(8-12 \mathrm{wt} . \%)$ and $\mathrm{Cr}(18-22 \mathrm{wt} . \%)$ provides the high-temperature protection of the alloy by forming a stable and continuous layer of chromia and/or alumina [29]. Ni is considered as the matrix and it forms a series of phases such as Ni-rich $\gamma-\mathrm{Ni}, \gamma^{\prime}-\mathrm{Ni} 3 \mathrm{Al}$, and Al-rich $\beta$-NiAl. Moreover, the coating ductility requirements greatly rely on the Ni content [30]. It should be noted that $\mathrm{Ni}$ can be substituted for $\mathrm{Co}$, when added, by which the addition of Co produces the $\beta-(\mathrm{Ni}, \mathrm{Co}) \mathrm{Al}$ phase and improves sulfidation resistance. In addition, Co has the ability to stabilize the phase equilibria in the $\mathrm{Ni}-\mathrm{Co}-\mathrm{Cr}-\mathrm{Al}$ system, by which it can limit the detrimental phase transformations during thermal cycling [27]. Further, only a small amount of $Y(\sim 0.5 \mathrm{wt} . \%)$ is added to the alloy composition for its desirable effects such as improving the thermallygrown oxide (TGO) adherence and preventing interfacial cavity formation [31][32].

Typically, a two-phase structure is reported for the MCrAlY alloys, composed of a ductile $\gamma$-phase (FCC structure) matrix with the embedded $\beta$-phase ( $\mathrm{CsCl}$ structure) precipitates. It should be noted that the elemental composition of alloys determines the number of phases and their specific temperature fields which they can form and exist. The presence of a minor amount of $\alpha$-Cr and $\sigma$-CoCr phases was also reported for some MCrAlY compositions. The former phase is attributed to the oversaturation of $\mathrm{Cr}$, which precipitates at cooling of $\alpha$-Cr particles, and the latter phase forms in the case of alloys with high content of $\mathrm{Cr}$ and $\mathrm{Co}$ [33]. It is worth noting that the main phase transformations, which occur at high-temperature exposure, involves the depletion of $\beta$-phase due to TGO formation and the inward diffusion of some alloying elements due to interdiffusion between the substrate and coating [34][35].

\section{Reinforcing Materials in MCrAlY Coatings}

Obtaining unique physical and chemical properties due to size effect has attracted increasing interest in studying the science and engineering of nanostructured coatings. The widespread class of the nanostructured coatings consists of various types of design models such as nano-scale multilayer coating, nano-graded coatings, and nanocomposite coatings, to name but a few [36]. A mixture of at least two phases, namely two nanocrystalline phases or an amorphous plus a nanocrystalline phase, comprises a nanocomposite coating. Usually, in the case of nanocomposite coatings, it is the reinforcement phase that has dimensions of $<100$ nanometers [37]. The importance of these coatings stems from the fact that they offer tailored property combinations for a wide array of applications, which are quite problematic to achieve using monolithic materials [36]. In other words, the single-phase coatings often cannot meet the multiple property requirements in many practical situations; therefore, it is rational to employ reinforced composite coatings [38].

So far, there have been extensive studies in the literature investigating the effects of the inclusion of various reinforcing materials in MCrAlY-based coatings. This is an indication that obtaining desired properties and the overall performance of composite coatings are significantly dependent on the right choice of reinforcing materials. In other 
words, this should be done in such a way that does not cause the formation of unwanted and deleterious phases. Particularly, this issue becomes more critical in high-temperature applications, where the oxidation performance plays a key role in the durability of coatings; therefore, the addition of reinforcement materials should not undermine the coatings' protective properties. It is also worth noting that for high-temperature tribology, thermal stability of the reinforcement materials is crucial [39]. In addition, it must be stressed that the term "reinforcement materials" in this paper mainly refers to the hard phases; therefore, the discussions on the effects of self-lubricating reinforcing phases such as $\mathrm{WS}_{2}$ are not included here.

In order to resolve the disadvantages of pure MCrAlY coatings, namely low wear resistance and low hardness, numerous studies are mostly channeled towards the incorporation of hard ceramic particles. Coatings with a specific composition of MCrAlY alloy, as matrix, can contain a wide array of reinforcing materials with different sizes, amounts, and types. Indeed, a crucial part of tailoring the reinforced coatings is achieved by the appropriate selection of reinforcements, which is highly customizable. Table 1 presents some properties of the reinforcing materials. The design methodology and preparation methods for the MCrAlY-based composite coatings are covered in the following section.

Table 1. Density and hardness values of various reinforcing materials [40][41][42][43][44][45].

\begin{tabular}{ccc}
\hline Material & Density $\left(\mathbf{k g} / \mathbf{m}^{3}\right)$ & Hardness $(\mathbf{G P a})$ \\
\hline $\mathrm{Al}_{2} \mathrm{O}_{3}$ & 3970 & $21-30$ \\
$\mathrm{Cr}_{2} \mathrm{O}_{3}$ & 5210 & $9-20$ \\
$\mathrm{ZrO}_{2}$ & 5750 & 10.7 \\
$\mathrm{CeO}_{2}$ & 7220 & $5-7$ \\
$\mathrm{TiO}_{2}$ & 4250 & $12-14$ \\
$\mathrm{ZrB}_{2}$ & 6120 & $15-23$ \\
$\mathrm{SiC}$ & 3210 & $24-32$ \\
$\mathrm{YSZ}$ & 5890 & 13.3 \\
$\mathrm{HfB}$ & 11212 & 28 \\
$\mathrm{TaC}$ & 14500 & 18.9 \\
\hline
\end{tabular}

\section{Incorporation Mechanisms of Particles into MCrAlY Coatings}

In general, the addition of hard second phase(s) to the MCrAlY coatings can be carried out through single or multiple steps. In the former procedure, the effort of feedstock preparation is omitted; however, it requires a close control of the deposition method. In most cases, the preparation of starting materials is necessary and is the first step. The feedstock materials could be in the form of rods, wires, and powders [46]. Powder feedstocks are preferable due to the denser corresponding coatings and having the greatest variety of materials manufactured for coating processes. Wire and rod feedstocks are limited to be used with specific processes such as arc spraying and flame spraying. The generally used techniques for the incorporation of reinforcements are mechanical alloying/milling, mechanical working, solid-state alloying, agglomeration and sintering, and mechanical mixing. In addition, an alternative approach for incorporating the strengthening particles into the coating's microstructure can be carried out through a controlled post heat treatment. This method utilizes the formation of oxide and oxy-nitride phases due to the entrapped oxygen inside the coating [47]. Table 2 presents a compilation of the reinforcement materials and their preparation techniques along with the applied coating process. 
Table 2. A summary of reported studies on the dispersion-strengthened MCrAlY-based coatings.

\begin{tabular}{|c|c|c|c|c|c|}
\hline Substrate & Matrix & Reinforcement(s) & Materials Preparation & $\begin{array}{l}\text { Coating Pro- } \\
\text { cess }\end{array}$ & Ref \\
\hline $\begin{array}{c}\text { Single crys- } \\
\text { tal superal- } \\
\text { loy (ERBO } \\
1) \\
\end{array}$ & CoNiCrAlY & $\mathrm{Al}_{2} \mathrm{O}_{3}$ & Mechanical milling & VPS & [9] \\
\hline $\begin{array}{l}\text { GH4169 } \\
\text { superalloy }\end{array}$ & CoCrAlYTa & $\mathrm{Al}_{2} \mathrm{O}_{3}$ & Cryomilling & $\begin{array}{c}\text { Laser-induc- } \\
\text { tion hybrid } \\
\text { cladding } \\
\end{array}$ & [23] \\
\hline AISI $316 \mathrm{~L}$ & NiCoCrAlY & $\mathrm{Al}_{2} \mathrm{O}_{3}$ & Mechanical alloying & HVOF & [48] \\
\hline Ti-6Al-4V & CoCrAlYTaSi & $\mathrm{Al}_{2} \mathrm{O}_{3}$ & Mechanical mixing & $\begin{array}{l}\text { Laser clad- } \\
\text { ding }\end{array}$ & [49] \\
\hline Inconel 718 & $\begin{array}{l}\text { CoCrA- } \\
\text { lYTaCSi }\end{array}$ & $\mathrm{Al}_{2} \mathrm{O}_{3}$ & $\begin{array}{c}\text { Agglomeration and Sin- } \\
\text { tering }\end{array}$ & $\mathrm{HVOF}$ & [50] \\
\hline GH4033 & NiCoCrAlY & $\mathrm{Al}_{2} \mathrm{O}_{3}, \mathrm{SiC}, \mathrm{CeO}_{2}$ & Mechanical milling & $\begin{array}{l}\text { Laser clad- } \\
\text { ding }\end{array}$ & [51] \\
\hline $\begin{array}{l}\text { Carbon } \\
\text { steel }\end{array}$ & NiCoCrAlY & $\mathrm{Al}_{2} \mathrm{O}_{3}, \mathrm{~B}_{4} \mathrm{C}$ & Solid-state alloying & APS & [52] \\
\hline $\begin{array}{c}\text { Stainless } \\
\text { steel }\end{array}$ & NiCoCrAlYTa & $\mathrm{Al}_{2} \mathrm{O}_{3}+\mathrm{Cr}_{2} \mathrm{O}_{3}$ & Mechanical mixing & APS & [53] \\
\hline $\begin{array}{l}\text { MDN321, } \\
\text { Superni } 76\end{array}$ & CoCrAlY & $\mathrm{NiCr}-\mathrm{Cr}_{3} \mathrm{C}_{2}$ & Mechanical mixing & APS & [54] \\
\hline Superni 76 & CoCrAlY & $\begin{array}{c}\mathrm{NiCr}-\mathrm{Cr}_{3} \mathrm{C}_{2}, \mathrm{WC}- \\
\mathrm{Co}\end{array}$ & Mechanical mixing & APS & [55] \\
\hline GH4169 & NiCrAlY & $\mathrm{TiO}_{2}-\mathrm{ZnO}$ & Mechanical mixing & APS & [56] \\
\hline IN-792 & NiCoCrAlYTa & $\mathrm{BN}$ & $\begin{array}{l}\text { Mechanical mixing + Sin- } \\
\text { tering into Electrode }\end{array}$ & $\begin{array}{c}\text { Electrospark } \\
\text { deposition }\end{array}$ & [57] \\
\hline Inconel-617 & CoNiCrAlY & YSZ & Mechanical milling & HVOF & [58] \\
\hline $\begin{array}{c}\text { Single crys- } \\
\text { tal superal- } \\
\text { loy } \\
\end{array}$ & NiCoCrAlYTa & $\mathrm{Y}_{2} \mathrm{O}_{3}$ & $\begin{array}{l}\text { Mechanical mixing }+ \text { Sin- } \\
\text { tering into Electrode }\end{array}$ & $\begin{array}{c}\text { Electrospark } \\
\text { deposition }\end{array}$ & [59] \\
\hline DZ 125 & NiCoCrAlY & $\mathrm{Al}_{2} \mathrm{O}_{3}$ & In-situ oxide dispersion & EB-PVD & [60] \\
\hline $\begin{array}{c}\text { Single crys- } \\
\text { tal superal- } \\
\text { loy } \\
\end{array}$ & NiCoCrAlYTa & $\mathrm{TaC}$ & $\begin{array}{l}\text { Mechanical mixing }+ \text { Sin- } \\
\text { tering into Electrode }\end{array}$ & $\begin{array}{c}\text { Electrospark } \\
\text { deposition }\end{array}$ & [61] \\
\hline- & NiCoCrAlY & $\mathrm{Al}_{2} \mathrm{O}_{3}$ & $\begin{array}{l}\text { Mechanical milling + } \\
\text { Spray drying }\end{array}$ & APS & [62] \\
\hline AISI 1035 & NiCrAlY & YSZ & Mechanical mixing & $\begin{array}{c}\text { Plasma trans- } \\
\text { ferred arc } \\
\text { (PTA) }\end{array}$ & [63] \\
\hline GH4033 & NiCoCrAlY & $\mathrm{Al}_{2} \mathrm{O}_{3}$ & Suspension mixing & $\begin{array}{l}\text { Laser clad- } \\
\text { ding }\end{array}$ & [64] \\
\hline Pure Ti & NiCoCrAlY & $\mathrm{ZrB}_{2}$ & Mechanical mixing & $\begin{array}{l}\text { Laser clad- } \\
\text { ding }\end{array}$ & [65] \\
\hline Pure Ti & NiCoCrAlY & $\mathrm{HfB}_{2}$ & Mechanical mixing & $\begin{array}{l}\text { Laser clad- } \\
\text { ding }\end{array}$ & [66] \\
\hline AISI H13 & CoNiCrAlY & $\mathrm{Cr}_{3} \mathrm{C}_{2}$ & $\begin{array}{l}\text { Agglomeration and Sin- } \\
\text { tering }\end{array}$ & HVOF & [67] \\
\hline GH4169 & NiCrAlY & $\mathrm{Ag}-\mathrm{MoO}_{3}$ & Mechanical milling & $\begin{array}{l}\text { Laser clad- } \\
\text { ding }\end{array}$ & [68] \\
\hline
\end{tabular}




\begin{tabular}{|c|c|c|c|c|c|}
\hline Steel & CoNiCrAlY & $\mathrm{Al}_{2} \mathrm{O}_{3}$ & Mechanical milling & HVOF & [69] \\
\hline $\begin{array}{l}\text { Stainless } \\
\text { steel }\end{array}$ & NiCrAlY & $\mathrm{Al}_{2} \mathrm{O}_{3}$ & Suspension mixing & $\begin{array}{c}\text { Hybrid } \\
\text { plasma spray }\end{array}$ & [70] \\
\hline $\begin{array}{l}\text { Low car- } \\
\text { bon steel }\end{array}$ & NiCoCrAlY & $\mathrm{CeO}_{2}+\mathrm{Al}_{2} \mathrm{O}_{3}$ & Mechanical milling & HVOF & [71] \\
\hline $\begin{array}{l}\text { Low car- } \\
\text { bon steel }\end{array}$ & NiCoCrAlY & $\mathrm{CeO}_{2}$ & Mechanical milling & HVOF & [72] \\
\hline- & NiCrAlY & $\mathrm{Al}_{2} \mathrm{O}_{3}+\mathrm{h}-\mathrm{BN}$ & Suspension mixing & $\begin{array}{c}\text { Hybrid } \\
\text { plasma spray }\end{array}$ & [73] \\
\hline Superni 76 & CoCrAlY & $\mathrm{Al}_{2} \mathrm{O}_{3}+\mathrm{YSZ}, \mathrm{CeO}_{2}$ & Mechanical mixing & APS & [74] \\
\hline AISI 304 & NiCrAlY & $\mathrm{Al}_{2} \mathrm{O}_{3}$ & Suspension mixing & HVOF & [75] \\
\hline GH536 & NiCrAlY & $\mathrm{Al}_{2} \mathrm{O}_{3}$ & Mechanical milling & $\begin{array}{c}\text { Argon } \\
\text { shrouded } \\
\text { plasma spray } \\
\text { (ASPS) }\end{array}$ & [76] \\
\hline T91 & NiCrAlY & $\mathrm{SiC}$ & Mechanical mixing & HVOF & [77] \\
\hline $\mathrm{T} 22$ & NiCrAlY & $\mathrm{B}_{4} \mathrm{C}$ & Mechanical mixing & HVOF & [78] \\
\hline TiAl & NiCoCrAlY & $\mathrm{SiC}$ & Suspension mixing & $\begin{array}{l}\text { Laser clad- } \\
\text { ding }\end{array}$ & [79] \\
\hline GH4169 & $\begin{array}{l}\text { NiCoCrAlY, } \\
\text { CoNiCrAlY }\end{array}$ & $\mathrm{Cr}_{2} \mathrm{O}_{3}$ & Solid-state alloying & APS & [80] \\
\hline $\begin{array}{l}\text { Superco- } \\
605\end{array}$ & CoCrAlTaY & $\mathrm{Al}_{2} \mathrm{O}_{3}$ & Mechanical mixing & HVOF & [81] \\
\hline Alloy 600 & NiCoCrAlY & YSZ & Mechanical milling & HVOF & {$[82]$} \\
\hline $\begin{array}{l}\text { Superni 76, } \\
\text { MDN } 321\end{array}$ & CoCrAlY & WC-Co & Mechanical mixing & APS & [83] \\
\hline IN-738 & CoNiCrAlY & $\mathrm{Al}_{2} \mathrm{O}_{3}$ & Mechanical milling & HVOF & [84] \\
\hline TiBw/Ti64 & CoCrAlY & $\mathrm{TiB}_{2}$ & Suspension mixing & APS & [85] \\
\hline $\begin{array}{l}\text { Ti-based } \\
\text { superalloy }\end{array}$ & CoCrAlSiY & YSZ & $\begin{array}{l}\text { Powder-mixing within } \\
\text { the feeding system }\end{array}$ & $\begin{array}{c}\text { Laser direct } \\
\text { deposition } \\
\text { (LDD) } \\
\end{array}$ & [86] \\
\hline AISI H13 & CoCrAlYTa & $\mathrm{Al}_{2} \mathrm{O}_{3}$ & $\begin{array}{l}\text { Agglomeration and Sin- } \\
\text { tering }\end{array}$ & HVOF & [87] \\
\hline Steel & NiCoCrAlY & $\mathrm{CeO}_{2}$ & Mechanical mixing & APS & [88] \\
\hline $\begin{array}{c}\text { Ni-base } \\
\text { superalloy }\end{array}$ & NiCoCrAlYTa & $\mathrm{TaC}$ & $\begin{array}{l}\text { Electrode forming by la- } \\
\text { ser casting wire }\end{array}$ & $\begin{array}{c}\text { Electrospark } \\
\text { deposition }\end{array}$ & [89] \\
\hline Mild steel & $\mathrm{NiCoCrAl}$ & $\mathrm{Al}_{2} \mathrm{O}_{3}-40 \% \mathrm{TiO}_{2}$ & $\begin{array}{l}\text { Powder-mixing within } \\
\text { the feeding system }\end{array}$ & APS & [90] \\
\hline $\begin{array}{l}\text { 316L Stain- } \\
\text { less steel }\end{array}$ & NiCoCrAlYTa & WC-Co & Mechanical mixing & $\mathrm{HVOF}$ & [91] \\
\hline Ti6Al4V & NiCoCrAlY & $\mathrm{CeO}_{2}$ & Mechanical milling & $\begin{array}{l}\text { Laser clad- } \\
\text { ding } \\
\end{array}$ & [92] \\
\hline Steel & CoNiCrAlY & $\mathrm{Cr}_{3} \mathrm{C}_{2}$ & $\begin{array}{c}\text { Commercially available } \\
\text { powders }\end{array}$ & HVOF & [93] \\
\hline $\begin{array}{l}\text { 304 Stain- } \\
\text { less steel }\end{array}$ & CoNiCrAlY & $\mathrm{Al}_{2} \mathrm{O}_{3}$ & Mechanical milling & HVOF & [94] \\
\hline Inconel 718 & NiCrAlY & $\mathrm{ZrO}_{2}$ & Mechanical mixing & $\begin{array}{l}\text { Ultrasonic-as- } \\
\text { sisted direct } \\
\text { laser deposi- } \\
\text { tion } \\
\end{array}$ & [95] \\
\hline
\end{tabular}




\begin{tabular}{|c|c|c|c|c|c|}
\hline $\begin{array}{c}\text { Heat-re- } \\
\text { sistant steel }\end{array}$ & NiCrAlY & $\mathrm{CeO}_{2}$ & $\begin{array}{c}\text { Ultrasonic gas atomiza- } \\
\text { tion }\end{array}$ & HVOF & {$[96]$} \\
\hline $\begin{array}{c}\text { Ni-based } \\
\text { superalloy } \\
\text { GH4033 }\end{array}$ & NiCoCrAlY & $\mathrm{Al}_{2} \mathrm{O}_{3}$ & Mechanical mixing & $\begin{array}{c}\text { Laser clad- } \\
\text { ding }\end{array}$ & [97] \\
\hline
\end{tabular}

\subsection{Feedstock Material Preparation}

Traditionally, different methods have been utilized for the addition of reinforcement materials into the matrix. Various forms of reinforcements have been used for this purpose, some common examples of which are whiskers, fibers, and particulates. Among these forms, the incorporation of particulates is of great interest, owing to the isotropic properties of the final composite and its easy manufacturing process. It should be taken into account that using large particles (tens to hundreds of micrometers) can lead to a reduction in ductility and toughness; hence, fine particles $(\leq 1 \mu \mathrm{m})$ must be used, in order to reach enhanced mechanical properties [98]. Besides, enhanced binding between the matrix and finer reinforcing materials has been reported, by which unfavorable effects like particle rebounding during thermal spraying can be prevented; therefore, higher content of the added materials would be maintained in the coating [99]. The reinforced MCrAlYbased alloys are considered as the metal-matrix composites (MMCs), in which a combination of good ductility and toughness along with the high strength and stiffness can be achieved. The overall properties of these MMCs are greatly affected by the size, volume fraction, type, morphology, and distribution of the added reinforcing particles [100]. Three of the possible patterns of reinforcement distribution within the matrix phase are depicted in Figure 2.

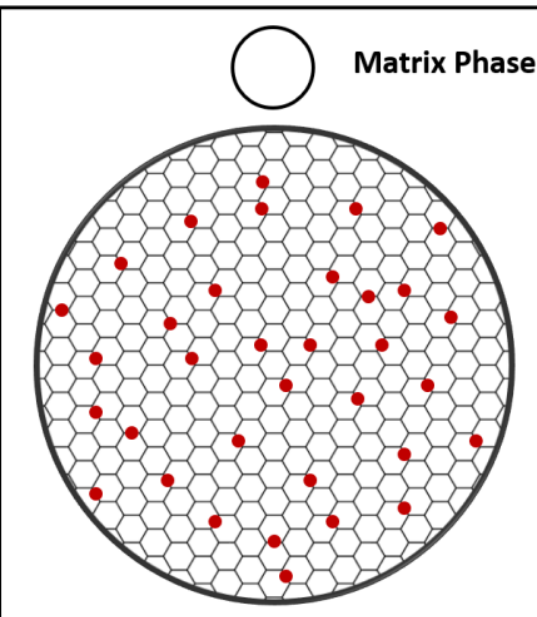

(a)

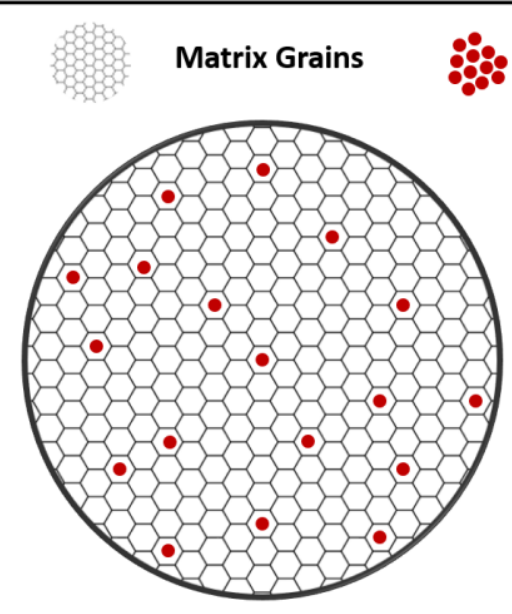

(b)

\section{Reinforcement Phase}



(c)

Figure 2. Schematic representing the possible distribution patterns of reinforcement phase within the matrix in an MMC; (a) The distribution of reinforcement phase along the grain boundaries of matrix, (b) The distribution of reinforcement phase inside the grains of matrix, and (c) A combined distribution pattern of both (a) and (b).

The most commonly used and preferred method for manufacturing pure MCrAlY feedstock is gas atomization. It involves injecting the liquid alloys inside a nozzle to an inert gas atmosphere (usually Ar), where it gets fragmented into spherical droplets and subsequent rapid solidification allows the homogeneous alloy formation [101]. Although there are many commercially available sources for MCrAlY powders, most of the studies covered in this paper have used a laboratory setup for synthesizing the desired feedstock composition. The following discussion will briefly describe two of the most used synthesis methods in the dispersion-strengthened MCrAlY literature. 


\subsubsection{Mechanical Mixing}

The preparation of starting materials through mechanical mixing or blending can be considered as one of the simplest and fastest routes to obtain the desired mixture for subsequent surface engineering treatments. Oftentimes, this process is carried out in a ball milling apparatus under dry or wet (suspension) conditions and does not involve any alloying or bonding. The main drawback associated with the mechanical mixing is the possibility of inhomogeneous dispersion of the reinforcement materials within the final coating. This condition can lead to different mechanical properties which vary with position; i.e. the loss of isotropic properties. In addition, the oxidation and decomposition of the reinforcements, especially the carbide type materials, pose a problem to the feedstock materials prepared via mechanical mixing [52]. That being said, the rapid and easy processing of this method result in lower production costs; thus, making it suitable for large scale production. Moreover, this process provides a good level of control over composition and does not alter the particle size and shape [102]. Accordingly, mechanical mixing is an efficient approach for mixing the reinforcing materials with the pre-alloyed MCrAlY powders; however, it is not a suitable synthesis route for producing the primary MCrAlY feedstock.

\subsubsection{Mechanical Milling and Alloying}

One of the most effective and well-established methods to obtain the metal matrix composite powders is the mechanical milling process [37]. Indeed, this process has been widely exploited for the preparation of MCrAlY-based micro- and nanocomposite powders [103]. Typically, the mechanical milling process starts with a powder charge, comprised of a blend of a matrix and one or more of the reinforcement materials together with the grinding media. In addition, producing MCrAlY powders with a fine dispersion of alumina is achievable through a controlled in-situ oxidation during the milling process [104]. The in-situ oxidation process is performed by adjusting the oxygen content inside the milling vial via precise control of the atmosphere (air, argon, nitrogen). Furthermore, the characteristics of the final product can vary depending on the objective of milling and its controlling parameters. During the milling, the powder particles are influenced by the energy transferred to them from the ball collisions. This can induce significant morphological changes and phase transformations. A schematic of the effect of collisions on powder particles along with the composite formation mechanism is provided in Figure 3. Moreover, Table 3 summarizes some of the studies reported on the development of modified MCrAlY-based powders via mechanical milling technique.

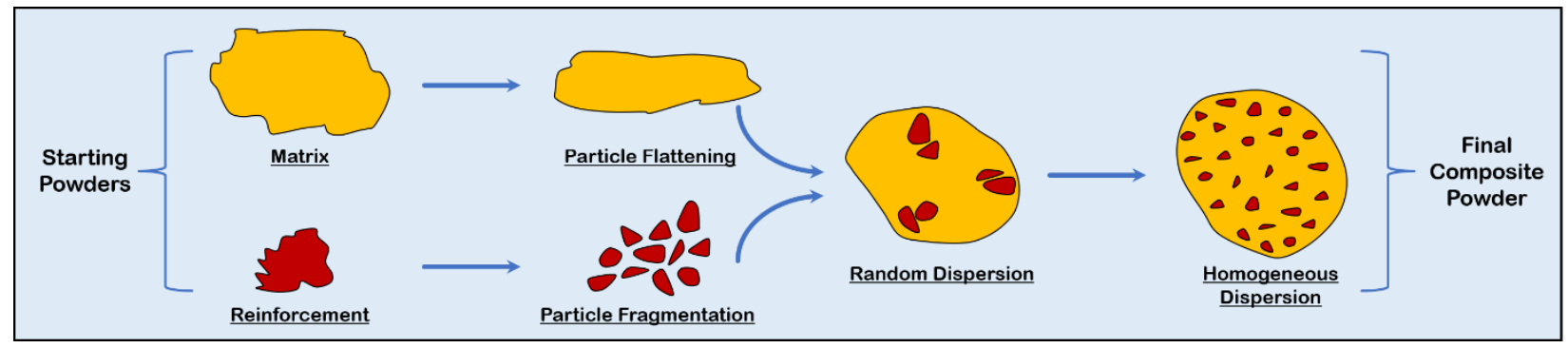

Figure 3. Schematic representing the deformation characteristics of powder particles upon collisions and the formation mechanism of composite powder. 
Table 3. Some highlights of the literature on the development of modified MCrAlY-based powders via mechanical milling technique.

\begin{tabular}{|c|c|c|c|}
\hline $\begin{array}{l}\text { Powder Compo- } \\
\text { sition }\end{array}$ & Milling Type & Observations & Ref \\
\hline $\begin{array}{c}\mathrm{CoNiCrAlY}+ \\
\mathrm{Al}_{2} \mathrm{O}_{3}\end{array}$ & $\begin{array}{l}\text { High-kinetic ball } \\
\text { milling device } \\
\text { (Simoloyer CM01) }\end{array}$ & $\begin{array}{l}\text { Longer milling times caused the hardening of powder } \\
\text { particles and an increase in the carbide contamination. } \\
\text { Adding higher contents of stearic acid, as the process } \\
\text { control agent (PCA), resulted in the elongated particles, } \\
\text { which were present in the HVOF-sprayed coatings as } \\
\text { well. } \\
\text { Conducting the milling process in a low-volume cham- } \\
\text { ber caused more collisions with higher energy input to } \\
\text { the powder particles. }\end{array}$ & [69] \\
\hline $\begin{array}{c}\text { NiCoCrAlY + } \\
\text { YSZ }\end{array}$ & $\begin{array}{l}\text { High-kinetic ball } \\
\text { milling device } \\
\text { (Simoloyer CM08) }\end{array}$ & $\begin{array}{l}\text { With a milling time not exceeding } 5 \mathrm{~h} \text {, powder particles } \\
\text { with a near-spherical morphology and a homogenous } \\
\text { dispersion of the added oxide phase were achieved. } \\
\text { The incorporation of YSZ into the NiCoCrAlY matrix } \\
\text { led to a drastic increase in the powder microhardness. } \\
\text { The strengthened powders showed a microhardness } \\
\text { value of } 660 \mathrm{HV} \text {, in comparison with the } 420 \mathrm{HV} \text { for } \\
\text { the commercial powder. }\end{array}$ & [82] \\
\hline $\begin{array}{c}\text { Pure } \\
\text { NiCoCrAlY }\end{array}$ & $\begin{array}{l}\text { Cryomilling with } \\
\text { an attrition mill } \\
\text { (Union Process 1- } \\
\text { D) }\end{array}$ & $\begin{array}{l}\text { The SEM observations revealed a flattened and flaky } \\
\text { morphology for the cryomilled powder. } \\
\text { The XRD analysis showed a single broad peak corre- } \\
\text { sponding to the } \gamma \text { phase, as opposed to the dual-phase } \\
(\gamma+\beta) \text { structure of the un-milled powder. }\end{array}$ & {$[105]$} \\
\hline $\begin{array}{c}\mathrm{NiCoCrAlYSi}+ \\
\mathrm{Al}_{2} \mathrm{O}_{3}\end{array}$ & $\begin{array}{l}\text { Cryomilling with } \\
\text { an attrition mill }\end{array}$ & $\begin{array}{c}\text { The spheroidal as-received powder went under a series } \\
\text { of morphological changes to rough oval-shaped parti- } \\
\text { cles ( } 8 \text { h-milled), irregular flake-shaped agglomerates } \\
\text { (12 h-milled), and large disk-like particles ( } 16 \mathrm{~h} \text { - } \\
\text { milled). } \\
\text { The addition of nano-sized } \mathrm{Al}_{2} \mathrm{O}_{3} \text { to the powder mix- } \\
\text { ture caused a number of changes such as lower ten- } \\
\text { dency for cold-welding, which resulted in very small- } \\
\text { sized particles, and an increase in the Fe content. }\end{array}$ & [106] \\
\hline $\begin{array}{c}\text { CoNiCrAlY + } \\
\text { YSZ }\end{array}$ & $\begin{array}{l}\text { High-energy plan- } \\
\text { etary ball mill }\end{array}$ & $\begin{array}{l}\text { It was suggested that the severe plastic deformation } \\
\text { due to the milling process caused the dissolution of } \beta \\
\text { phase into the } \gamma \text { phase of the matrix. } \\
\text { An increase in the amount of YSZ resulted in the brit- } \\
\text { tleness of powder mixture and delayed the cold-weld- } \\
\text { ing phenomenon during the milling; therefore, the final } \\
\text { powder particles with higher reinforcement were finer. }\end{array}$ & {$[107]$} \\
\hline $\begin{array}{c}\text { Pure } \\
\text { CoNiCrAlY }\end{array}$ & $\begin{array}{l}\text { Cryomilling with } \\
\text { an attrition mill } \\
\text { (Union Process } \\
\text { model 01-HD) }\end{array}$ & $\begin{array}{l}\text { Cryomilling under the severe processing conditions } \\
\text { (higher charge ratio and longer times) caused a signifi- } \\
\text { cant increase in the average powder particle size above } \\
\qquad 100 \mu \mathrm{m} \text {. } \\
\text { Particle coarsening with a flake-like morphology was } \\
\text { observed in the case of cryomilled powders. } \\
\text { The TEM study revealed the nanostructure of the cry- } \\
\text { omilled powders with a grain size of } 20 \pm 7 \mathrm{~nm} \text {. }\end{array}$ & [108] \\
\hline
\end{tabular}


Further, the presence of Al oxides and oxy-nitrides were detected by this analysis.

It must be noted that mechanical milling is affected by various process controlling parameters and is a highly stochastic process [109]. With this in mind, a wide range of milling conditions used for the preparation of reinforced MCrAlY feedstocks implies that there is no distinct instruction, and care should be exercised to optimize the prime parameters for desirable results.

\subsection{Feedstock Material Deposition}

When it comes to the choice of the deposition process, careful consideration must be given to the coating material chemistry with its design requirements and component geometry, while reaching economic and desired property objectives. An acceptable deposition technique must also be compatible with the substrate material in terms of its chemical and physical constraints [110]. Some of the widely employed processing methods for the deposition of MCrAlY-based coatings are reviewed below.

\subsubsection{Thermal Spraying}

The thermal spraying process can be defined as a technique in which coating materials, including metallic or nonmetallic types, are deposited on a substrate by undergoing a series of events such as heating, acceleration, and plastic deformation upon impact where solidification and splats build-up occur to form the desired coating [111]. The coatings obtained from these techniques are known as overlay coatings, in which the coating materials are added to the substrate's surface with no diffusion or dilution. Furthermore, these processes offer distinct benefits, including the possibility of depositing coatings with a wide thickness range onto different components without the limitations of complex geometries [46]. Other technological advantages of these methods include flexibility of depositing broad range of materials, high productivity, and capability of applying localized repairs to recover the damaged components [16].

Some classifications have been established for the different thermal spraying processes. A widely accepted approach is to divide them according to the heat or energy source and two of the most widely used thermal spraying technologies for depositing the wear-resistant coatings are HVOF and APS [9]. Figure 4 depicts a general concept of this process. Some of the main factors affecting the final thermally-sprayed coatings' properties are listed below and an appropriate processing window should be chosen with reference to the feedstock material properties and the microstructure of the corresponding coating [46].

- $\quad$ Spraying parameters (i.e., power and gas supply, material feeding rate, stand-off distance)

- $\quad$ Spray torch type

- $\quad$ Coating material preparation (i.e., powder morphology and size distribution, flowability, deformability)

- $\quad$ Surrounding atmosphere (i.e., atmospheric air, controlled shielding atmosphere, vacuum)

- $\quad$ Substrate material, surface preparation, and its cooling

In addition to the thermal spraying techniques themselves, it is also pertinent to emphasize the contribution of the supporting hardware technologies such as robots for spray gun handling, mass flow controllers, and computer-operated control units. The incorporation of these associated technologies has played a key role in the improvement of coating quality and ensuring reliability [17][112]. 


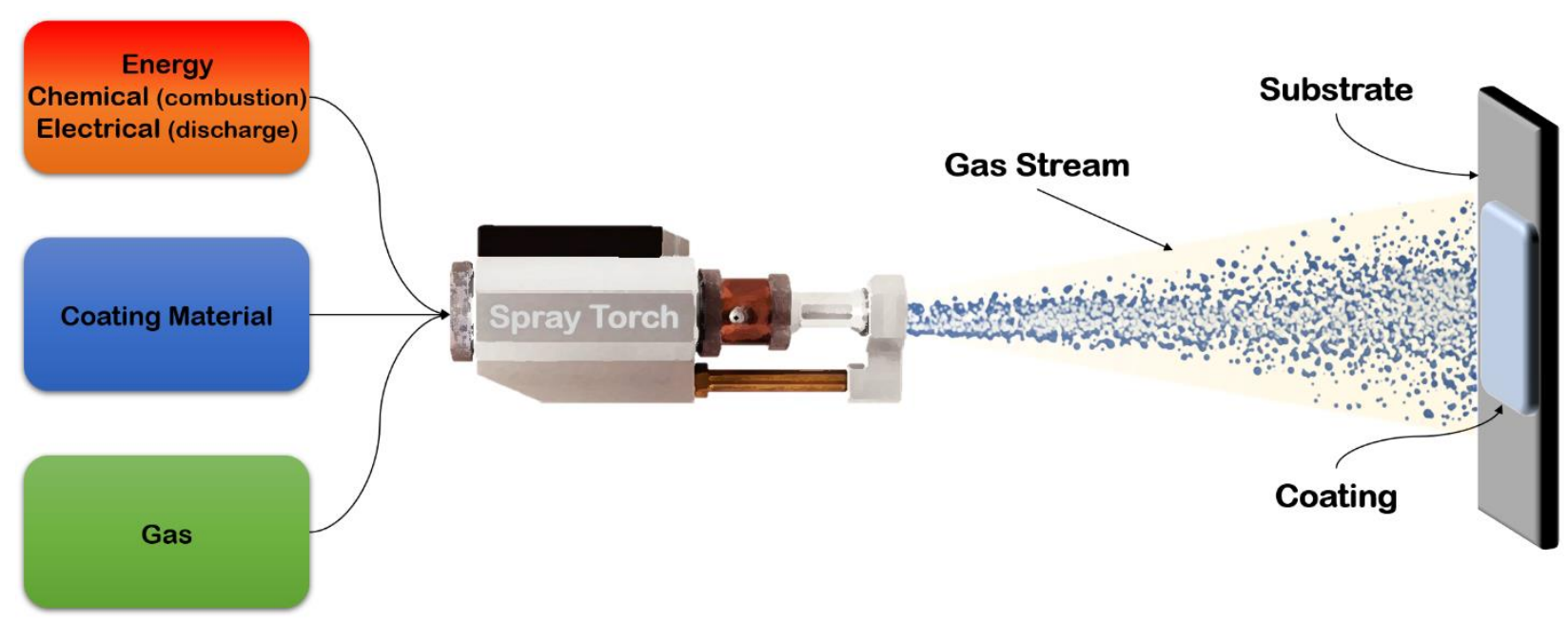

Figure 4. Schematic representing the thermal spray concept.

Owing to the high flexibility and good adaptability of different thermal sources and equipment configurations, a variety of different techniques belongs to the thermal spray family. Each of these deposition techniques produce coatings with unique microstructures and are constantly being developed. Overall, these techniques are differentiated on the account of flame temperature, particle speed, and spray atmosphere [113]. In the following, the most commonly used thermal spraying technologies for the fabrication of MCrAlY-based coatings are reviewed and their working principles are briefly described.

\section{- $\quad$ Plasma spraying}

The APS technique is a versatile process with a high cost/performance ratio, which has been successfully utilized as a reliable solution for a plethora of industrial challenges. As a general rule, thermal spraying can be applied to deposit virtually any type of material, which can be melted without causing decomposition. It is reported that a minimum temperature difference of $300 \mathrm{~K}$ between the melting and decomposition temperature is suitable for the sprayable materials [114]. In this regard, owing to the high flame temperature, APS shows great flexibility with respect to the sprayable materials [115][116]. It appears that this flexibility is one of the main driving criteria for the rapid development of this technique.

The gas plasma produced either by radio-frequency (RF) discharge or direct current (DC) arc is used as the heat source of the APS technology. A typical plasma torch used for the APS deposition is comprised of a water-cooled copper, as anode, and a thoriated tungsten, as cathode. Moreover, a flow of working gases with the typical compositions of $\mathrm{Ar}+$ $\mathrm{H}_{2}$, $\mathrm{Ar}+\mathrm{N}_{2}$, and $\mathrm{Ar}+\mathrm{He}$ is used for the formation of a plasma jet [46]. These gases are divided into two main groups; primary and secondary ones. Oftentimes, Ar is used as the primary gas and its major role is to stabilize arc within the nozzle [117]. Furthermore, performing under ambient conditions has made the APS technology an economically attractive manufacturing process, which is best suited for depositing high-quality ceramic coatings. In the case of metallic powders, the APS-sprayed coatings may suffer from inflight oxidation; however, this can be ameliorated through spraying in a vacuum atmosphere. With this in mind, vacuum plasma spray (VPS) or, as sometimes called, low-pressure plasma spray (LPPS) technique has been developed, by which coatings without any pores and insignificant oxide contents can be produced. That being said, employing a vacuum system increases the operation costs by an order of magnitude [118].

- High-velocity oxy/air-fuel (HVOF/HVAF) spraying

The invention of the HVOF process goes back to the 1958; however, it did not find industrial use until the early 1980s, when new spray systems with the improved commercial viability were introduced. In principle, the HVOF process operates with combustible gases (as energy sources) such as propane, propylene, and hydrogen, which combust with 
oxygen (as oxidizer gas); resulting in the formation of a supersonic expansion of the combusting mixture. It is to be noted that in gas-fueled systems, accommodation of the environment (reducing or oxidizing) is possible by adjusting the oxygen/fuel ratios. Also, a series of HVOF guns were developed using liquid fuels, like kerosene. The guns with this design allow powders to be injected radially instead of axial injection and improves the operational safety at reduced costs [111]. It should be noted that the fuel type selection is based on both economic and technical factors, including availability, price, and purity [17]. Besides, in comparison with the APS method, HVOF provides higher spraying velocities, lower particle temperature, and low exposure time of the particles to flame. These features give rise to obtaining coatings with low porosity, good adhesion, and low content of oxides. Furthermore, progress in utilizing different nozzle configurations has enabled higher gas velocities and, as a result, producing denser coatings [119].

Another emerging thermal spray variant is called high-velocity air-fuel (HVAF), which offers highly adherent coatings with insignificant porosity levels due to the higher powder velocities. Compared to HVOF, the HVAF process is also benefited from its lower flame temperatures $\left(<1950{ }^{\circ} \mathrm{C}\right)$, which in turn, leads to negligible in-situ thermal damage such as oxidation and decarburization [120]. It should be noted that both of the mentioned techniques are combustion-based, and the main difference is the oxidizer; as it is pure oxygen for the HVOF process whereas compressed air is used in HVAF process. According to Gärtner et al. [121], the ultimate goal for designing the HVOF systems was to achieve reduced particle temperature and increased velocity. These criteria were almost met with the third generation HVOF systems, which employ an approximate chamber pressure of $1 \mathrm{MPa}$. This value can reach $2 \mathrm{MPa}$ in the case of HVAF systems. These characteristics make the HVAF process a particularly appropriate technique for developing novel corrosion- and wear-resistant coatings.

- Cold spraying

The cold spraying technology is a powder deposition process occurring at solid-state and temperatures much lower than the conventional thermal spraying processes. In this technique, a high-pressure and pre-heated gas (typically nitrogen) is used to accelerate the micron-sized particles $(<50 \mu \mathrm{m})$ to high velocities in order for the feedstock powder to impact and bond to a substrate, resulting from the associated viscoplastic deformation [122][123]. For the most modern high-pressure cold spraying systems, a converging-diverging (de Laval type) nozzle is utilized to reach supersonic velocities. Further, due to the fact that the feedstock material exists in the solid-state during the spraying process; thus, the previously mentioned drawbacks of other thermal spraying methods, including thermal damage and temperature-dependent structural changes, can be alleviated to a great extent [124].

The feasibility of this process for the satisfactory deposition of MCrAlY alloys has been analyzed in the literature and the results show promising potential, which could be gainfully utilized with further experimental tests [125][126][127]. Further, the potential of depositing nanocrystalline MCrAlY coatings by using solely the cold spraying method is reported [128][129]. Achieving higher hardness due to grain size reduction and formation of strong bonding at the coating-substrate interface are favorable features for an improved tribological performance.

- $\quad$ Suspension and hybrid plasma spraying

The conventional thermal spray techniques have proven successful in the deposition of MCrAlY-based composites onto a wide array of substrate materials and have gained industrial acceptance. That being said, the processing of fine modified powders is one of the major limitations of these methods. In other words, injecting small and low-density powder particles into a high-energy stream is problematic. To address this issue, a novel and innovative technique for the composite coating deposition was proposed and patented by Gitzhofer et al. [130] called suspension plasma spray (SPS). Nowadays, other configurations of this technology have also been developed which employ a dual-feed or hybrid plasma spray system. The hybrid processing takes the advantage of simultaneous feeding of both the dry powder (matrix) and the liquid suspension (reinforcement). To do 
so, a modified thermal spray apparatus is used to process a suspension injection in addition to the conventional powder feeding system. Since the reinforcement materials consist of very fine particles, they cannot be appropriately delivered through a carrier gas; therefore, utilizing a liquid carrier makes sense, as it provides adequate flowability to these fine particles. The superiority of this process lies in the fact that there is no feedstock preparation needed before spraying; however, the dispersion of the added reinforcement materials will not match the coatings obtained by depositing the mechanically milled powders. This is because, in hybrid plasma spraying, the reinforcement phase can solely be located between the matrix lamellae [70]. Moreover, it is worth noting that agglomeration of the small-sized solid reinforcements is quite likely during SPS. Additionally, feedstock sedimentation during storage might be a major concern of this method [117]. A schematic of a typical set-up used for the hybrid plasma spray along with the coating architecture are shown in Figure 5.

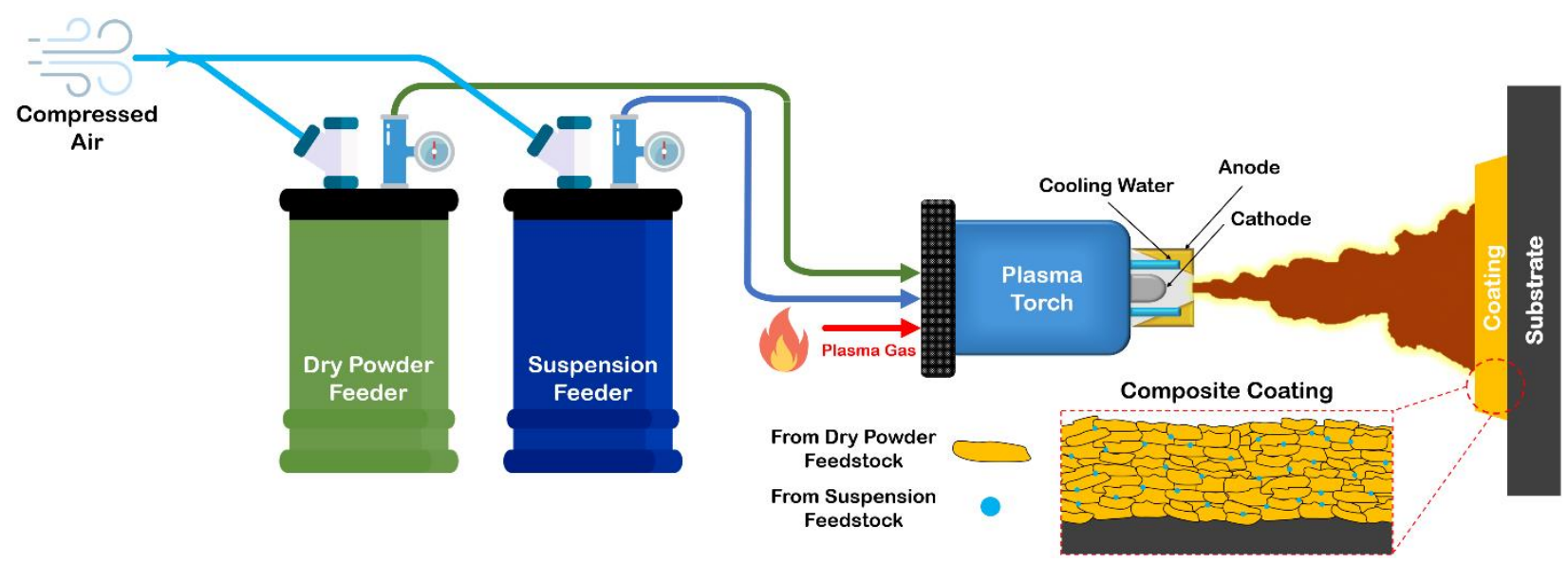

Figure 5. Schematic representing the hybrid plasma spray set-up and the composite coating architecture.

\subsubsection{Electrospark Deposition}

Electrospark deposition (ESD) is an electrical pulsed-arc micro-welding technique that deposits electrode materials using short interval high-current pulses which are discharged at monitored energy levels. This method has the ability to produce micro- and nano-crystalline structures which are metallurgically bonded to the substrate surface. When compared to the laser cladding process, it causes low thermal impact to the metallic substrate. Moreover, adjusting the pulse frequency and energy gives a high flexibility to obtain various deposition conditions. It has been reported that utilizing low frequency with high energy can rapidly result in a thick coating, whereas a high frequency and low energy is preferable for achieving superior coating surface quality [131].

\subsubsection{Laser Cladding}

Owing to the precision and flexibility of lasers, the laser-based processes have gained a considerable potential and interest in the materials engineering and surface processing. Since the 1980s, the laser-cladding technology (also termed as laser surface alloying) has been proven to be a superior alternative to the conventional cladding methods and it has been vastly implemented industry-wide. This is largely due to the desirable characteristics offered by the laser-cladding process such as low dilution in response to the confined heat input and an overall limited number of defects [132].

In simple terms, laser cladding can be defined as a type of laser welding in which stacked build-ups of many single weld beads are aligned onto a substrate. It has been adopted in a wide array of applications, in which the structural components are used in corrosive and/or abrasive environments [133][134]. In terms of material supply, laser cladding operates in two different configurations; wire and powder-based. The alloy powder 
delivery into the melt pool can be done through either injecting at an angle or by coaxial injection along the laser beam. Moreover, the process is not limited to metals, and dispersions of ceramics can be used to functionalize the obtained parts [135]. A typical laser cladding machine is shown schematically in Figure 6. It consists of a process zone, processing head with a laser source, and powder delivery nozzles.



\section{Scanning Direction}

Figure 6. Schematic representing the laser cladding process.

As an alternative to the thermal spray techniques, laser cladding has received significant attention as an effective and rapid method for the deposition of MCrAlY-based coatings [136][137]. Specifically, the coaxial laser cladding process has been successfully tested to manufacture dense coatings by using a special nozzle head, which provides the overlapped individual laser tracks [138]. It is worth noting that controlling the process parameters is of utmost importance in obtaining a high-quality continuous coating and preventing the common material defects, including cracks, pores, and lack of fusion [139]. As mentioned earlier (Figure 1), the coating/substrate adhesion is one of the major characteristics of a suitable coating, which fulfils the function of protection against the tribological failures at high temperatures. In the case of laser-cladded MCrAlY-based coatings, the resultant adhesion strength is significantly dependent on the interfacial strength, residual stresses, and bonding defects. It has been reported that the formed diffusion zone between the substrate and coating plays a key role in the resultant mechanical properties and achieving a reduced chemical dilution of the coating to substrate exhibits more desirable outcomes [140]. 


\section{Microstructure and Phase Composition}

Most of the existing knowledge on the corrosion-wear behavior of bulk materials can be used to explain and interpret for the case of coatings; however, the unique characteristics of coating microstructures and phase compositions must be considered. Moreover, these characteristics strongly affect the mechanical and tribological response of coatings; therefore, it is imperative to provide and understand a proper microstructural characterization of coatings.

\subsection{Thermally-Sprayed Coatings}

As discussed earlier, particles experience high temperatures and achieve high speeds during the thermal spray processes. This condition results in the formation of wavy layers or lamellae, typically known as splats, which adhere to the substrate material upon impact at its surface. Generally, the commercially available gas-atomized powders are used as the feedstock for thermal spraying; however, for depositing the reinforced composites, a batch of feedstock materials should be prepared before spraying. As each preparation method produces various feedstock materials with certain characteristics, the obtained microstructure of the corresponding thermally-sprayed coatings can distinctly vary.

In general, features including oxide content, phases, cracks, porosity, and bond strength are of utmost importance in determining the mechanical and tribological properties of thermally-sprayed coatings. It is worth adding that the surface preparation plays a key role in the coating adhesion property [141]. This is because the coating adhesion is mainly achieved by the mechanical anchorage to the underlying substrate; therefore, an efficient surface preparation treatment is essential [142]. An optimum preparation of the component surface for producing well-adherent coatings involves cleaning with alcohol solutions and grit blasting, by which a surface roughness $\left(\mathrm{R}_{\mathrm{a}}\right)$ of $4-8 \mu \mathrm{m}$ is obtained. Okada et al. [84] investigated the influence of HVOF spraying parameters on the microstructure of alumina-reinforced CoNiCrAlY coatings. They have reported that obtaining a dense, pore-free and unoxidized coating demands adequately high flame temperatures in order to properly melt the added reinforcement, while the metallic part of the coating material does not oxidize. They have also suggested that performing the milling stage for longer times can produce smaller size powders, which are more likely to melt at lower flame temperatures. It is worth adding that the presence of un-melted particles, as a result of higher melting point of the incorporated reinforcements, has been observed even in the case of plasma-sprayed coatings [56].

As is well-known, the deposit structure greatly affects the properties of thermallysprayed coatings. Critical variables related to the chemical and physical state of particles in thermal spraying, such as degree of melting, velocity, and temperature, strongly rely on the process parameters [143]. Owing to the fact that improving the coating performance necessitates the optimization of these parameters, a great number of experimental studies has been done on this issue [144][145][146]. Additionally, a modelling and simulation approach has also been taken in process parameter optimization for thermal spray techniques. This is because some aspects of the thermal spray process, including the particle in-flight behavior and gas dynamics, cannot be comprehensively understood with the experimental investigations [147][148][149][150][151].

Among the commonly used thermal spray methods for the deposition of strengthened MCrAlY coatings, the APS technology has the highest flame temperature ( 12000 $\left.{ }^{\circ} \mathrm{C}\right)$. According to this, coatings with a higher oxide content levels can be expected. A study on the APS-sprayed CoCrAlY-TiB 2 composite coating showed that Al oxide can be formed during the deposition process and end up being embedded inside the coating's microstructure. The formation of $\mathrm{Al}_{2} \mathrm{O}_{3}$ is mainly attributed to its high thermodynamic tendency of oxidation, which occurs as the air reacts with the molten droplets in plasma stream. Moreover, the high flame temperature can induce phase transformation during the deposition. Shi et al. [56] studied the NiCrAlY- $\mathrm{TiO}_{2}-\mathrm{ZnO}$ composite coating formed by the APS technology. They have reported that the typical $\gamma^{\prime}-\mathrm{Ni} 3 \mathrm{Al}$ phase was absent in the XRD 
pattern of the coating, which was related to the rapid solidification associated with the APS process. Further, they have identified a crystalline transition of $\mathrm{TiO}_{2}$ from anatase to rutile and a solid reaction during the APS spraying, which resulted in the formation of $\mathrm{Zn}_{2} \mathrm{TiO}_{4}$ phase. On account of the mentioned phenomena, a careful selection of the depositing process for each type of the feedstock materials is essential.

As noted by Hao et al. [91], the addition of materials with high melting point as the reinforcements can have a considerable impact on the microstructure and phase composition of the coatings. In their study, WC-Co-reinforced NiCoCrAlYTa coatings were deposited by the HVOF process, and it was observed that the insufficient melting of W during spraying had reduced the coatings' compactness. Moreover, further addition of the WC-Co content into the coatings caused an increase in the crystallinity of the major phases due to the weakening of rapid quench effect.

The localized plastic deformation and inter-particle adhesion have a considerable effect on the porosity and tensile strength of the composite coatings. In the case of $\mathrm{Al}_{2} \mathrm{O}_{3}-$ $\mathrm{B}_{4} \mathrm{C}$-strengthened $\mathrm{NiCoCrAlY}$ coatings, it was found that the coating porosity increased with an increase in the $\mathrm{B}_{4} \mathrm{C}$ contents. Also, a decrease in the tensile strength of the composite coatings with higher contents of the added $\mathrm{B}_{4} \mathrm{C}$ was noted. Furthermore, a lower particle deformability in the case of mechanically milled powders was also reported [152][153]. This condition can lead to the formation of pin-holes onto the coating surface and inter-particle pores within the coating.

Observations of Hatami et al. [39] indicated that adding too much of the reinforcing material might deteriorate the microstructure of the thermally-sprayed coatings, in terms of their oxide content and porosity. The findings of this research revealed that the addition of 15 wt. \% YSZ to a CoNiCrAlY matrix could increase the porosity up to $5.4 \%$, as compared to the $<0.2 \%$ for the unmodified coating. This was because of the undesirable powder morphology, as a result of milling with high contents of ceramic particles, which led to the unsatisfactory splat formation. Moreover, it has been reported that the crack initiation and propagation during the metal-to-metal contact conditions are promoted by the presence of porosity [154]. In this manner, attempts should be made to control the porosity in the coating microstructure.

Different types of residual stresses are also reported for the thermally-sprayed coatings, which influence their mechanical properties. The fast cooling of splats results in the generation of quenching stress, which is always tensile. Another important type of the stresses which is encountered in the thermal spray process is the compressive stress. This type stems from the high-velocity particles impact and is dependent on the coating temperature, as well as the kinetic energy of the airborne particles. Moreover, high-temperature gradients during the deposition process can induce phase transformations, which introduces a new phase with the different-sized crystal. This phase change can lead to the generation of residual stresses and must be avoided, especially for the low thermal conductivity coatings [155].

\subsection{Electrospark-Deposited Coatings}

The work due to Xie and Wang [57] indicated that obtaining MCrAlY/BN composite coatings by ESD technique does not yield high-quality results. In this study, it was noted that by increasing the BN content, the coatings' microstructure changed from thick and dense with good metallurgical bonding to deteriorated microstructure in terms of high porosity and formation of cracks with large inclusion phases. The unfavorable experimental results were mainly attributed to the decomposition of BN reinforcement during ESD process, in which secondary phases had formed and reacted with the alloying elements of MCrAlY matrix. In a subsequent study by the same authors [89], TaC was utilized as the reinforcement in a NiCoCrAlYTa matrix. All of the coatings obtained in this study were shown to be fully dense and no evidence of cracks or discontinuities in the coating-substrate interface were observed. Furthermore, it was noticed that the TaC dispersed particles within the coting retained their primary morphology which was seen in 
the electrode microstructure. This is in contrast with the results obtained from ESD coatings containing other ceramic particles such as $\mathrm{Y}_{2} \mathrm{O}_{3}$ and $\mathrm{TiC}$, where they get melted and preferentially solidified as nuclei [156][157]. It is worth noting that the different behaviors are mainly related to the melting point of the reinforcement materials, among which TaC had the highest melting point $\left(3880{ }^{\circ} \mathrm{C}\right)$. It was concluded that the added $\mathrm{TaC}$ particles did not melt and were directly transferred to the substrate along with the molten matrix.

The voltage value is one of the determining parameters in the ESD process and it has a significant influence on the energy of the capacitor discharge $\left(E \propto V^{2}, E\right.$ and $V$ being the energy and voltage, respectively) [158]. Wang et al. [59] carried out a systematic study on the formation and growth kinetics of NiCoCrAlYTa- $\mathrm{Y}_{2} \mathrm{O}_{3}$ composite coatings influenced by the operating voltage. It was reported that increasing the voltage increased the diameter of the deposit, which in turn produced thinner deposit thickness. Besides, a shift from a gentle morphology to more intense one, in terms of splash and crater features, was observed with the increase of the voltage. Further examination of the coatings showed epitaxial growth and a dense structure with random distribution of some micro-pores; however, the turbulent nature of the molten deposit caused by the voltage increase led to the formation of lack of fusion defect. Moreover, a homogeneous dispersion of yttria particles was seen in inter-dendritic and dendrite core regions. The transferring stage of the added foreign particles during the ESD process could occur both in molten and solid-state. Noting the high transient temperature of the electrospark (5000-10000K) [156], it is reasonable to assume that all of the materials would melt and then transferred; nevertheless, the short exposure time to high-temperature enables the solid-state transfer.

In a study by Wang et al. [61], a NiCoCrAlYTa-TaC composite coating was produced by ESD process on a single crystal superalloy. Initially, they investigated the hot-pressed electrode materials and found out that the addition of $\mathrm{TaC}$ led to a descending trend in both thermal diffusivity and thermal conductivity as a function of temperature. Also, the dispersion pattern of the added TaC was in between the NiCoCrAlYTa powders' boundaries. Considering this, it was suggested that the $\mathrm{TaC}$ particles distributed in the powder boundaries had caused an increase in the contact thermal resistance; consequently, reduced the two aforementioned properties. Furthermore, the investigation of coatings exhibited dense structure with metallurgical bond to the substrate. The quite intact structure of the substrate-coating interface implied negligible heat impact of the ESD process. Moreover, examining the phase composition of coatings showed that the dominant peaks switched from (111) to (200), confirming the directional solidification.

\subsection{Laser-Cladded Coatings}

Owing to the desirable features of the laser-cladded MCrAlY-based coatings, they have become of interest in the recent years and a great proportion of the literature has focused on these coatings. Considering the harmful influence of the porosity and oxide inclusions, which are typically present in the case of thermally-sprayed coatings, producing dense coatings with limited oxygen uptake makes the laser-cladding process a favorable method for depositing the MCrAlY-based alloys.

Since it is expected that the addition of reinforcement materials might change the coating microstructure; hence, it is necessary to explore its influence and make an effort to optimize the deposition process. A microstructural investigation on the $\mathrm{Al}_{2} \mathrm{O}_{3}$ dispersion-strengthened NiCoCrAlY coating exhibited the significant effect of nano alumina addition on the laser cladded coatings' microstructure [64]. It was found that by adding $\mathrm{Al}_{2} \mathrm{O}_{3}$, the coating-substrate interface changed from directional and epitaxial dendrites to cellular and thinner ones. Moreover, it was detailed that the incorporation of alumina acted as the heterogenous nucleation sites in the molten pool, in which activated the simultaneous nucleation in greater number of regions and discontinued the uniform growth of dendrites. In addition, a preventive effect against the formation of holes and cracks was attributed to the presence of $\mathrm{Al}_{2} \mathrm{O}_{3}$. This was due to the fact that alumina particles 
increased the latent heat of fusion; thereby, the melting point of the cladding layer was reduced and generation of hot-stresses due to the temperature gradient was inhibited.

In an attempt to lengthen the service life of a Ti-6Al-4V alloy substrate, Weitong and Dejun [49] fabricated CoCrAlYTaSi coatings with 15, 30, and 45 wt.\% $\mathrm{Al}_{2} \mathrm{O}_{3}$, as reinforcement, by the laser cladding technique. They have observed an increase in the porosity of the obtained coatings with the increase of $\mathrm{Al}_{2} \mathrm{O}_{3}$ mass fraction. It was indicated that the presence of $\mathrm{Al}_{2} \mathrm{O}_{3}$ in the powder mixture accelerated the cooling rate; thus, there was not enough time for the laser cladding induced gas to escape, by which it led to the formation of pores. Further cross-sectional examinations revealed the influence of $\mathrm{Al}_{2} \mathrm{O}_{3}$ on the coating-substrate bonding. It was found that the enriched zones of $\mathrm{Al}_{2} \mathrm{O}_{3}$ with a strong convection effect were formed at the middle and bottom parts of coatings where they caused a disordered interface. This was due to the change in the cooling and heating transfer of substrate during the deposition process. Moreover, the phase analysis confirmed the structural stability of the added $\mathrm{Al}_{2} \mathrm{O}_{3}$, which implies the small thermal radiation of the deposition process. That being said, some cases of phase transformation have been reported for the laser cladded coatings. As an example, the laser cladding of NiCoCrAlY$\mathrm{ZrB}_{2}$ composite powder on a pure $\mathrm{Ti}$ substrate has resulted in the formation of several new phases, including $\mathrm{TiB}$ and $\mathrm{Ni} 3 \mathrm{Zr}$ [65]. The reason for this can be ascribed to the dilution effect caused by the substrate melting, by which it promotes reactions between the $\mathrm{Ni}$ and Ti matrix along with the decomposed $\mathrm{ZrB}$. These discrepancies in the microstructure and phase composition stem from the different equipment and parameters used for the deposition process.

Jiaxing et al. [92] studied the effects of $\mathrm{CeO}_{2}$ addition on the formation and microstructure of the final NiCoCrAlY coating. They noted that $\mathrm{CeO}_{2}$ could increase the fluidity of molten pool and its heat transfer; thereby, forming a micro-serrated type bonding of coating with the substrate with enhanced bond strength and reduced crack sensitivity.

It is worth highlighting a potential shortcoming for the laser cladding of reinforced MCrAlY alloys. If the selected reinforcement is comparatively lighter than the MCrAlY matrix $\left(\sim 7.5 \mathrm{~g} / \mathrm{cm}^{3}\right)$, then there would be a possibility of floating during the coating process, in which most of the reinforcement content segregate on the upper regions of coating. On the other hand, if the selected reinforcement is comparatively heavier than the MCrAlY matrix, then it would tend to segregate at the coating-substrate interface. This can result in promoting crack initiation in sliding contact conditions [159].

Another potential issue with the laser-cladded MCrAlY coatings containing reinforcing materials is related to the formation of a heterogeneous microstructure. This can be attributed to the poor wettability of MCrAlY matrix and added reinforcements, in which reinforcements tend to agglomerate. A successful approach to overcome this problem is by utilizing laser deposition technology along with ultrasonic vibration. Yi et al. [95] used a direct laser deposition technique under ultrasonic vibration for the preparation of $\mathrm{ZrO}_{2}-$ reinforced NiCrAlY coatings. Prior to employing ultrasound-assisted technique, the obtained specimens exhibited undesirable macroscopic morphology with numerous oxide scales at the surface, which were spalled after during the cooling period. It was found that the agitation and stirring effects of ultrasound resulted in coatings with smoother and flatter surfaces. Also, hindering the agglomeration of added $\mathrm{ZrO}_{2}$ improved the overall microstructural homogeneity.

\section{Experimentation and Instrumentation for Mechanical and Tribological Measure- ments}

MCrAlY coatings are extensively utilized in a variety of industries, which demand certain properties. Concerning the structural components experiencing sliding contacts, characterization and measurement of the mechanical and tribological characteristics are essential in the qualification of the coatings for applications. The commonly used experiments for mechanical and tribological studies of materials, involve using different forms of indentation and tribometer systems. Development of a wide variety of mechanical and 
tribological tests, as well as various instruments and equipment, have enabled the researchers to measure different properties and explore the mechanical/tribological response of materials. These techniques should be accurate, effective, and repeatable in order for a design engineer to use them either for further optimization of materials in full production or finding and developing novel structural materials [160][161]. Some typical methods are briefly mentioned below.

\subsection{Evaluation of Mechanical Properties}

Hardness, adhesion, fracture toughness, elastic modulus, and shear modulus are among the main mechanical properties of materials. Two of the main factors in determining these properties include the manufacturing method and material composition. Accordingly, cross-comparing different materials obtained from different techniques does not provide a reasonable assessment and comparison of their performance. Further, it is always a good idea to perform a few complementary testing and measurement, or even make effort to replicate the coatings' real conditions in the experiments [46].

- Adhesion

Many adhesion tests have been developed based on fracture mechanics, and are used in both academic and industrial settings [117]. The tensile adhesion test (TAT), which is specified in the ASTM C633 or ISO 14916:2017 standards, is the most prevalent procedure in determining the adhesion strength. There can be more than one bonding mechanisms in a typical coating and due to the complexity of accurate measurement of each mechanism, a comprehensive methodology is explored in laboratory tests to determining bond strength that is representative of the overall coating system [162].

- Hardness

Hardness measurement is relatively simple and is frequently examined. In most of the studies, the test is performed using the indentation method. The measurement techniques are identified by an indenter, like Vickers and Knoop, which are the most wellknown indenters [117]. Other approaches for determining micro- and nano-hardness have been developed by the researchers as well, by which the test provides information on mechanical properties such as elastic modulus [163]. It is worth adding that micro-indentation hardness testing is the prevalent and recommended technique for the MCrAlY-based coatings, as opposed to the macro-indentation tests. This is due to the limited allowable size of the indent imprint on these coatings which usually have average thicknesses of less than $1 \mathrm{~mm}$ [162].

- $\quad$ Elastic modulus

Another mechanical feature in the evaluation of coatings is the elastic modulus. There are two types of testing methods for this property: destructive and non-destructive [46]. The destructive procedures include several testing methods such as indentation technique, tensile and compression tests, and cantilever beam testing. The non-destructive approaches include ultrasonic spectroscopy and laser acoustic testing, which are highly sensitive to coating defects [117]. The traditional evaluation of elastic modulus is done by examining the slope of linear section of the obtained stress-strain curve. By surpassing the elastic limit, yielding and fracturing would follow through plastic deformation. Moreover, due to the different distribution of defects in coatings with the identical composition and deposition method, obtaining a diverse array of Ec values is anticipated [162].

It is well-known that service conditions of MCrAlY-based coatings involve elevated temperatures; thus, special attention should be devoted to the temperature-induced changes on the mechanical properties. Indeed, these properties play a critical role in the mechanical integrity of overall system under the thermally cycled conditions [164]. That being said, due to the challenging test conditions, the existing experimental results on the high-temperature mechanical properties of MCrAlY-based coatings are scarce. Waki et al. [165] developed a successful lateral compression setup, by which the Young's modulus and bending strength of thermally-sprayed CoNiCrAlY coatings were measured at 920 ${ }^{\circ} \mathrm{C}$. This study utilized circular tube specimens and induction heating was used to reach 
the experimental temperature. In a study by Texier et al. [140], a mechanical test rig was implemented to examine the tensile behavior of NiCoCrAlYTa coating at $1100{ }^{\circ} \mathrm{C}$. The tensile experiments were performed with free-standing micro-tensile samples and under displacement control.

\subsection{Evaluation of Tribological Properties}

Abrasive, adhesive, and erosive wear are the most common mechanisms encountered in tribological contacts. To assess the tribological performance of coatings, grasping an understanding of these complex wear mechanisms is necessary, which can be done using the standard test methods [117]. There are three main configurations for this purpose, (i) pin-on-disc, (ii) ball-on-flat, and (iii) block-on-ring as shown in Figure 7. The two first tests employ a pin or ball as the counter body; some common examples of which are WC-Co, $\mathrm{Al}_{2} \mathrm{O}_{3}$, stainless steel, and $\mathrm{Si}_{3} \mathrm{~N}_{4}$. All three of the tests determine wear volume loss to estimate wear rate, which is performed by analyzing surface topography or measuring mass loss. Further, the system is induction-heated to study the influence of increased temperature and a thermocouple is used for monitoring. After reaching the specified temperature, an isothermal condition is maintained for the high-temperature tests [70].

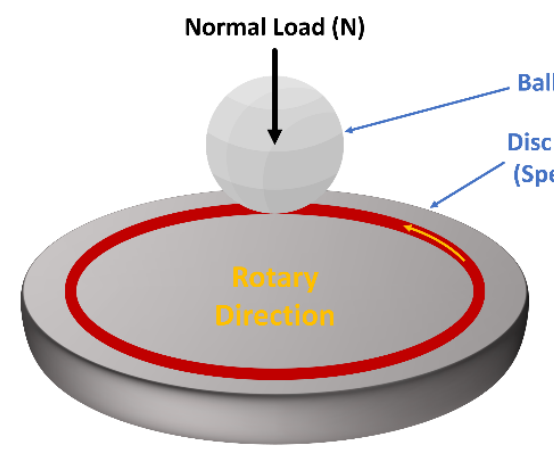

(a) Pin-on-Disc ASTM G 99 (b) Ball-on-Flat ASTM G 133

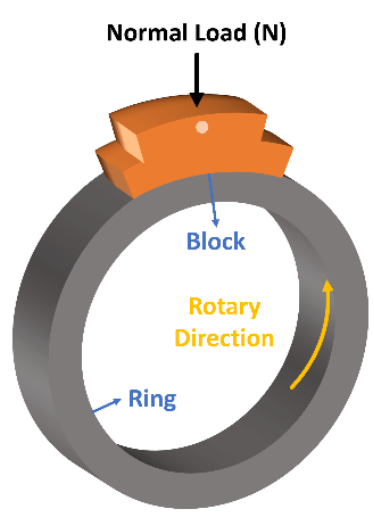

(c) Block-on-Ring ASTM G 77

Figure 7. Schematic representing the three main configurations for wear test along with the corresponding ASTM standard.

Two of the most common erosion testers include gas-blast erosion and centrifugal erosion designs. The design of former tester was taken from the commercial sand blasting equipment and the basis involve enabling pressurized gas to expand by passing a narrow tube, by which the velocity of gas flow increases. After feeding a steady stream of abrasive particles, the drag force from the high-velocity gas accelerates these particles. Lastly, the accelerated particles impact the specimen fixed at a predetermined distance. Further, the influence of impact angle can be evaluated by rotating the specimen holder at a specified angle to the incoming gas stream. The principle of centrifugal erosion tester is based on accelerating the abrasive particles by imposing centrifugal force. In this test, radially positioned tubes are utilized for particle flow in a rotating disc, and the specimens are positioned around the disc's circumference. A splitter located at the center of the disc is used to deliver the abrasive particles [166]. ASTM G76-13 and ASTM G211-14 are two standards that define experimental conditions for laboratory erosion tests at ambient and elevated temperatures, respectively. Also, some guidelines can be found in the literature, mainly focusing on the erosion tests of coatings [167]. 


\section{Mechanical and Tribological Properties}

The satisfactory coating materials for the sliding parts of industrial equipment operating at ambient and elevated temperatures demand good mechanical and tribological properties along with high oxidation performance. The investigations conducted on reinforced MCrAlY coatings have shown promising characteristics in a broad temperature range. In this section, the mechanical and tribological properties together with the most important affecting factors for these coatings at ambient and high temperatures are summarized.

\subsection{Hardness}

The hardness test is commonly used in the mechanical evaluation of coatings, and, in simple terms, its result reflects the resistance to plastic deformation caused by an indenter placing in a perpendicular direction. In addition, not only is it a useful parameter for ranking different coatings when comparing them, but also it can provide more information such as the elastic properties. It should be noted that, notwithstanding the simplicity of this test, which is typically done by measuring the dimensions of an indentation left, it should be treated with caution to ensure that the associated errors are minimized. The measured hardness values are also influenced by the residual stresses built up during the coating processing. In this connection, large stresses could lead to considerable variations and exaggeration in hardness readings, which can be prevented by performing a stress-relief annealing treatment, if it does not cause any significant structural changes [161]. Overall, the extrinsic nature of hardness, as materials property, should be considered in investigations. This is because, factors such as loading mode, indenter shape, and the size of applied load can greatly affect the hardness values [160]. A compilation of hardness data for MCrAlY-based composite coatings is shown in Figure 8.

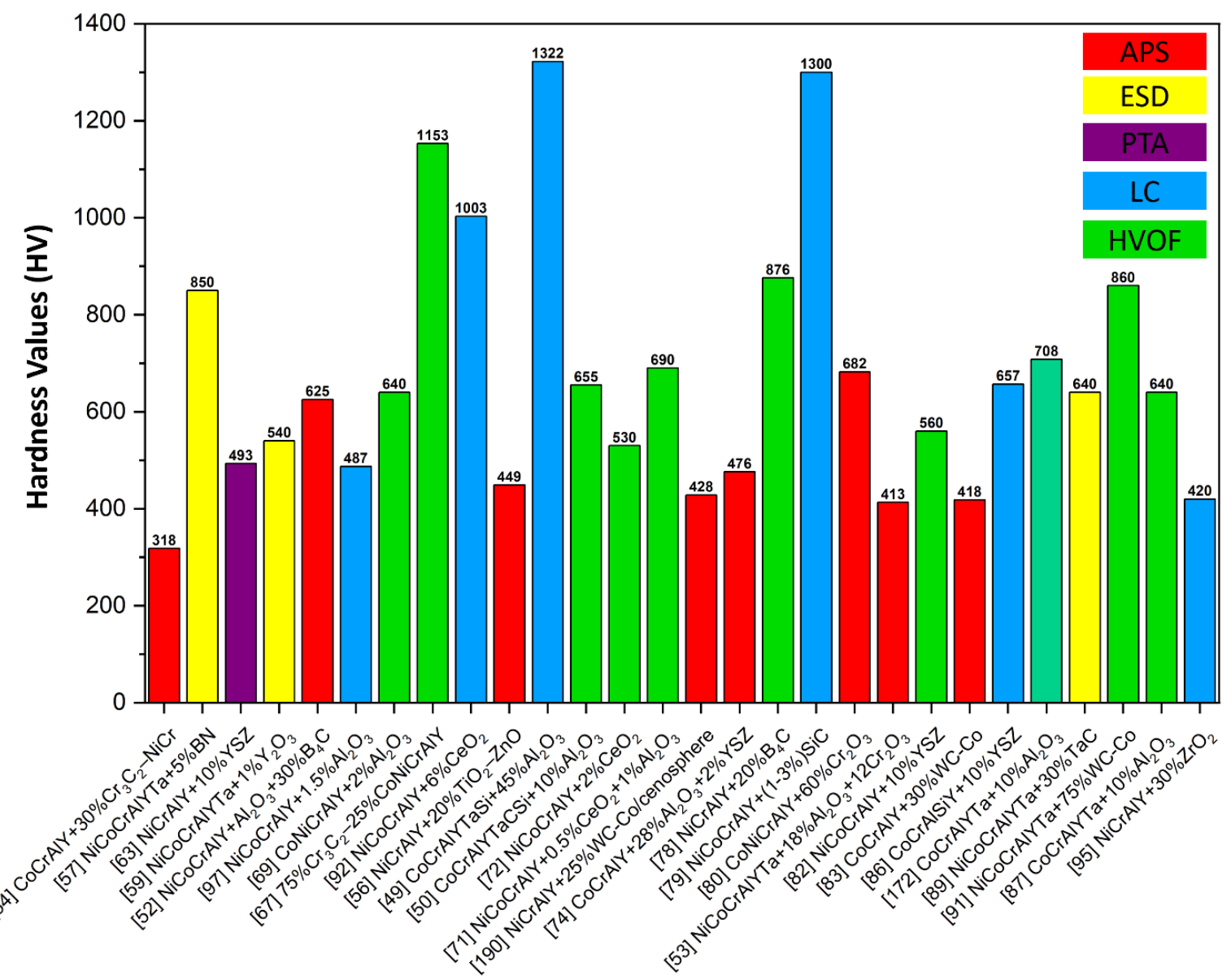

Figure 8. Hardness comparison of MCrAlY-based coatings reinforced with different materials. 
Yanliang et al. [23] examined $\mathrm{Al}_{2} \mathrm{O}_{3}$-reinforced CoCrAlYTa coatings and ascribed the increase of microhardness to higher volume fraction of $\beta$ phase in the case of $\mathrm{Al}_{2} \mathrm{O}_{3}$ added coatings. In their study, the nanohardness values obtained for each constituting phase confirmed that the $\beta$ phase ( 9.8 GPa) exhibited higher values compared to the $\gamma$ phase ( $7.5 \mathrm{GPa})$, and the alumina particle addition did not influence these properties. Further, presence of higher $\beta$-NiAl content in the NiCoCrAlY matrix increased its mean hardness (393 $\mathrm{HV}_{0.1}$ ) compared to the CoNiCrAlY matrix (365 $\mathrm{HV}_{0.1}$ ), which were deposited via HVOF process [168].

The formation of oxide layer(s) on the coating surface could significantly affect the hardness values. As will be discussed in section 7.4.2, various types of oxides can cover the surface of MCrAlY-based coatings at high temperatures. Hao et al. [169] studied the effect of oxidation time on the mechanical properties of HVOF-sprayed NiCoCrAlYTa coatings. They found that the highest hardness of $29.20 \mathrm{GPa}$ was measured by nano-indentation after $50 \mathrm{~h}$ of oxidation at $1000{ }^{\circ} \mathrm{C}$. This was notably higher than that of the assprayed coating (10.50 GPa), which is mainly due to the formation of hard and compact alumina layer. Further extending the oxidation time resulted in less hardness values and it was ascribed to the formation of other mixed-type oxides, such as $\mathrm{NiCr}_{2} \mathrm{O}_{4}$ and $\mathrm{CoCr}_{2} \mathrm{O}_{4}$.

In a study [61], effects of $\mathrm{TaC}$ reinforcement and oxidation were investigated for an electrospark-deposited NiCoCrAlYTa coating. Prior to oxidation, the microhardness examinations across the coating exhibited an increasing trend from surface toward the interface. This was suggested to be related to the refined microstructure of dendrites near the interface. A considerable decrease in hardness values were observed following oxidation. As concluded by the authors, it seems that the outward diffusion of $\gamma^{\prime}$ stabilizers (Al and Ta) resulted in the $\gamma^{\prime} \rightarrow \gamma$ phase transformation, and consequently caused lower hardness. Moreover, the oxidized reinforced coating showed comparable hardness values across the coating than that of the un-oxidized conventional coating.

The effects of $\mathrm{Al}_{2} \mathrm{O}_{3}$ content and testing temperature were explored for NiCrAlY coatings [70]. The as-sprayed coatings and those held at $400{ }^{\circ} \mathrm{C}$ had roughly equivalent hardness levels with a slight increase up to $12 \mathrm{wt}$ \% $\mathrm{Al}_{2} \mathrm{O}_{3}$-added coating. The minor variations in hardness were related to the limited cohesion between particles $\left(\mathrm{Al}_{2} \mathrm{O}_{3}\right)$ and matrix (NiCrAlY) lamellae. Besides, it was suggested that the occurrence of interface sliding between the matrix and reinforcement was further limiting the load transfer; hence, constraining the increase in hardness. Moreover, increasing the alumina content up to $18 \mathrm{wt} \%$ resulted in reduced hardness values, which was ascribed to the formation of microstructural defects by particles clustering. On the other hand, a significant increase in hardness values was observed for samples tested at $700{ }^{\circ} \mathrm{C}$. This improvement was due to the combined effects of enhanced intra-lamellar strength and inter-lamellar cohesion. Moreover, it was noted that the enhanced trends in hardness were insensitive to the reinforcement effect.

\subsection{Adhesion}

Adhesion, or sometimes bond strength, refers to a coating's capability to stay attached to the substrate under specified in-service conditions. This ability could be considered as the most important feature of a coating, since if it's adhesion strength to the substrate is insufficient, then the surface's performance may be degraded. Interfacial debonding failure takes place as the coating fails to stay bonded to the substrate and can cause surface failure through the crack nucleation and propagation. It should be noted that the complexity under different conditions may result in mixing up the failure type (adhesive or cohesive), and care must be employed in testing. Moreover, similar to hardness evaluation, the adhesion strength will vary depending on the testing method and different loading conditions. As a result, it is critical to describe the exact contact conditions when determining adhesion strength and/or investigating the coating debonding mechanisms [161]. 
Sun et al. [96] explored the effects of ceria addition to the NiCrAlY powders via an ultrasonic gas atomization process. They reported that the modified powder particles were refined and had more uniform and narrow size distribution. The obtained properties for feedstock powder resulted in the formation of refined microstructure with less defects such as oxides and pores during the HVOF spraying. Due to these favorable characteristics, the $\mathrm{CeO}_{2}$-added coating exhibited improved hardness and adhesive strength. Further, the adhesion strength was evaluated for $\mathrm{CeO}_{2}$ and $\mathrm{Al}_{2} \mathrm{O}_{3} / Y S Z$ reinforced CoCrAlY coatings in [74]. The former reinforcement resulted in higher adhesion strength (15.65 MPa), and the observations of fractured surfaces confirmed adhesive failure mechanism. This is due to the fact that the coating's cohesive strength was higher than the adhesion strength between coating and substrate.

\subsection{Friction-Wear Performance}

Wear failures have significantly impacted most of the engineering industries worldwide, from both the economic and technical point of view. The promise of enhanced performance and extended durability is driving the interest in research and development of improved solutions for protection of the wear-prone parts. In fact, there is a close link between the wear resistance of components and the reduction in the cost of operation due to the reduced need for replacement and/or overhaul frequency [170]. 
Table 4. Compilation of friction-wear studies on the dispersion strengthened MCrAlY coatings.

\begin{tabular}{|c|c|c|c|c|c|c|c|c|}
\hline $\begin{array}{c}\text { Coating (Pro- } \\
\text { cess) }\end{array}$ & $\begin{array}{l}\text { Test config- } \\
\text { uration }\end{array}$ & $\begin{array}{l}\text { Abrasion } \\
\text { media }\end{array}$ & $\begin{array}{l}\text { Applied } \\
\text { load }\end{array}$ & $\begin{array}{c}\text { Test fre- } \\
\text { quency/spee } \\
\text { d }\end{array}$ & $\begin{array}{c}\text { Test dis- } \\
\text { tance/time }\end{array}$ & $\begin{array}{c}\text { Test tempera- } \\
\text { ture }\end{array}$ & $\begin{array}{l}\text { Best friction-wear } \\
\text { resistance }\end{array}$ & Ref \\
\hline $\begin{array}{l}\mathrm{CoNiCrAlY-} \\
\mathrm{Al}_{2} \mathrm{O}_{3} \text { (VPS) }\end{array}$ & Ball on disc & $\mathrm{Al}_{2} \mathrm{O}_{3}$ & $5 \mathrm{~N}$ & $0.20 \mathrm{~m} / \mathrm{s}$ & $2500 \mathrm{~m}$ & $750{ }^{\circ} \mathrm{C}$ & $\begin{array}{c}\sim 3 \times 10^{-6} \\
\left(\mathrm{~mm}^{3} \mathrm{~N}^{-1} \mathrm{~m}^{-1}\right)\end{array}$ & [9] \\
\hline $\begin{array}{l}\text { CoCrAlYTa- } \\
\mathrm{Al}_{2} \mathrm{O}_{3} \\
(\mathrm{LC}) \\
\end{array}$ & Block on ring & $\begin{array}{c}\text { GCr15 } \\
\text { steel }\end{array}$ & $196 \mathrm{~N}$ & $400 \mathrm{rpm}$ & $600 \mathrm{~m}$ & $\mathrm{RT}$ & $5.58 \times 10^{-3}(\mathrm{mg} / \mathrm{m})$ & [23] \\
\hline $\begin{array}{c}\text { CoCrAlYTaSi- } \\
\mathrm{Al}_{2} \mathrm{O}_{3} \\
(\mathrm{LC}) \\
\end{array}$ & Ball on disc & $\mathrm{Si}_{3} \mathrm{~N}_{4}$ & $3 \mathrm{~N}$ & --- & $120 \mathrm{~m}$ & $800{ }^{\circ} \mathrm{C}$ & $\begin{array}{c}0.3 \times 10^{-4} \\
\left(\mathrm{~mm}^{3} \mathrm{~N}^{-1} \mathrm{~m}^{-1}\right)\end{array}$ & [49] \\
\hline $\begin{array}{c}\mathrm{NiCrAlY}- \\
\mathrm{TiO}_{2}-\mathrm{ZnO} \\
(\mathrm{APS}) \\
\end{array}$ & Ball on disc & $\mathrm{Al}_{2} \mathrm{O}_{3}$ & $10 \mathrm{~N}$ & $0.105 \mathrm{~m} / \mathrm{s}$ & $3600 \mathrm{~s}$ & $25,400,800{ }^{\circ} \mathrm{C}$ & $\begin{array}{c}7.3 \times 10^{-6} @ 800^{\circ} \mathrm{C} \\
\left(\mathrm{mm}^{3} \mathrm{~N}^{-1} \mathrm{~m}^{-1}\right)\end{array}$ & [56] \\
\hline $\begin{array}{c}\mathrm{CoNiCrAlY-} \\
\mathrm{Cr}_{3} \mathrm{C}_{2}(\mathrm{HVOF})\end{array}$ & Pin on disc & WC-6Co & $30 \mathrm{~N}$ & $0.10 \mathrm{~m} / \mathrm{s}$ & $\begin{array}{c}5 \times 10^{5} \text { cy- } \\
\text { cles }\end{array}$ & $25^{\circ} \mathrm{C}$ & $\begin{array}{c}2.8 \times 10^{-16} \\
\left(\mathrm{~m}^{3} \mathrm{~N}^{-1} \mathrm{~m}^{-1}\right)\end{array}$ & [67] \\
\hline $\begin{array}{c}\mathrm{NiCrAlY}-\mathrm{Al}_{2} \mathrm{O}_{3} \\
\text { (Hybrid } \\
\text { plasma spray) }\end{array}$ & Ball on disc & $\begin{array}{l}\text { Sintered } \\
\mathrm{Al}_{2} \mathrm{O}_{3}\end{array}$ & $5 \mathrm{~N}$ & $0.10 \mathrm{~m} / \mathrm{s}$ & $2000 \mathrm{~m}$ & $\begin{array}{c}\mathrm{RT}, 400,700 \\
{ }^{\circ} \mathrm{C}\end{array}$ & $\begin{array}{c}\sim 5 \mathrm{x} 10^{-6} @ \mathrm{RT} \\
\sim 8 \times 10^{-5} @ 400{ }^{\circ} \mathrm{C} \\
\sim 2 \mathrm{x} 10^{-5} @ 700{ }^{\circ} \mathrm{C} \\
\left(\mathrm{mm}^{3} \mathrm{~N}^{-1} \mathrm{~m}^{-1}\right)\end{array}$ & [70] \\
\hline $\begin{array}{c}\mathrm{NiCrAlY}- \\
\mathrm{Al}_{2} \mathrm{O}_{3}-\mathrm{hBN} \\
\text { (Hybrid } \\
\text { plasma spray) } \\
\end{array}$ & Ball on disc & $\begin{array}{l}\text { Sintered } \\
\mathrm{Al}_{2} \mathrm{O}_{3}\end{array}$ & $5 \mathrm{~N}$ & $0.10 \mathrm{~m} / \mathrm{s}$ & $2000 \mathrm{~m}$ & $\begin{array}{c}\mathrm{RT}, 400,700 \\
{ }^{\circ} \mathrm{C}\end{array}$ & $\begin{array}{c}\sim 1 \times 10^{-5} @ \mathrm{RT} \\
\sim 3.5 \times 10^{-5} @ 400{ }^{\circ} \mathrm{C} \\
\sim 0.5 \times 10^{-5} @ 700{ }^{\circ} \mathrm{C} \\
\left(\mathrm{mm}^{3} \mathrm{~N}^{-1} \mathrm{~m}^{-1}\right)\end{array}$ & [73] \\
\hline $\begin{array}{c}\text { CoCrAlYTa- } \\
\mathrm{Al}_{2} \mathrm{O}_{3} \text { (HVOF) }\end{array}$ & Ball on disc & $\mathrm{Si}_{3} \mathrm{~N}_{4}$ & $10 \mathrm{~N}$ & $15.9 \mathrm{~Hz}$ & $60 \mathrm{~min}$ & $25-600{ }^{\circ} \mathrm{C}$ & $\begin{array}{c}\sim 3 \times 10^{-5} \\
\left(\mathrm{~mm}^{3} \mathrm{~N}^{-1} \mathrm{~m}^{-1}\right) @ 600 \\
{ }^{\circ} \mathrm{C} \\
\end{array}$ & [87] \\
\hline $\begin{array}{c}\text { NiCoCrAlYTa- } \\
\text { WC-Co } \\
\text { (HVOF) }\end{array}$ & Ball on disc & $\begin{array}{l}\text { GCr15 } \\
\text { steel } \\
\text { WC-Co }\end{array}$ & $5 \mathrm{~N}$ & $10 \mathrm{~cm} / \mathrm{s}$ & $200 \mathrm{~m}$ & RT & $\begin{array}{c}3.19 \times 10^{-6}(\mathrm{GCr} 15) \\
3.13 \times 10^{-6}(\mathrm{GCr} 15) \\
\left(\mathrm{mm}^{3} \mathrm{~N}^{-1} \mathrm{~m}^{-1}\right)\end{array}$ & [91] \\
\hline $\begin{array}{c}\text { NiCoCrAlY- } \\
\mathrm{CeO}_{2}(\mathrm{LC})\end{array}$ & Ball on disc & $\mathrm{Si}_{3} \mathrm{~N}_{4}$ & $3 \mathrm{~N}$ & 500 r.min ${ }^{-1}$ & $30 \mathrm{~min}$ & $600{ }^{\circ} \mathrm{C}$ & $\begin{array}{c}2.35 \times 10^{-7} \\
\left(\mathrm{~mm}^{3} \mathrm{~N}^{-1} \mathrm{~m}^{-1}\right)\end{array}$ & [92] \\
\hline $\begin{array}{l}\text { NiCoCrAlY- } \\
\mathrm{Al}_{2} \mathrm{O}_{3}(\mathrm{LC}) \\
\end{array}$ & Pin on block & $\mathrm{Al}_{2} \mathrm{O}_{3}$ & $20 \mathrm{~N}$ & $0.1 \mathrm{~m} / \mathrm{s}$ & $120 \mathrm{~m}$ & $500{ }^{\circ} \mathrm{C}$ & $\begin{array}{c}102.25 \times 10^{-6} \\
\left(\mathrm{~mm}^{3} \mathrm{~N}^{-1} \mathrm{~m}^{-1}\right)\end{array}$ & [97] \\
\hline
\end{tabular}

\subsubsection{Important Factors for Friction-Wear}

Wear is a complex phenomenon that is influenced by the factors shown in Figure 9. Indeed, in today's industrialized society, cases of interacting components in relative motion are extensive and occur frequently. As a result, determining wear and its mechanisms are challenging [46]. 


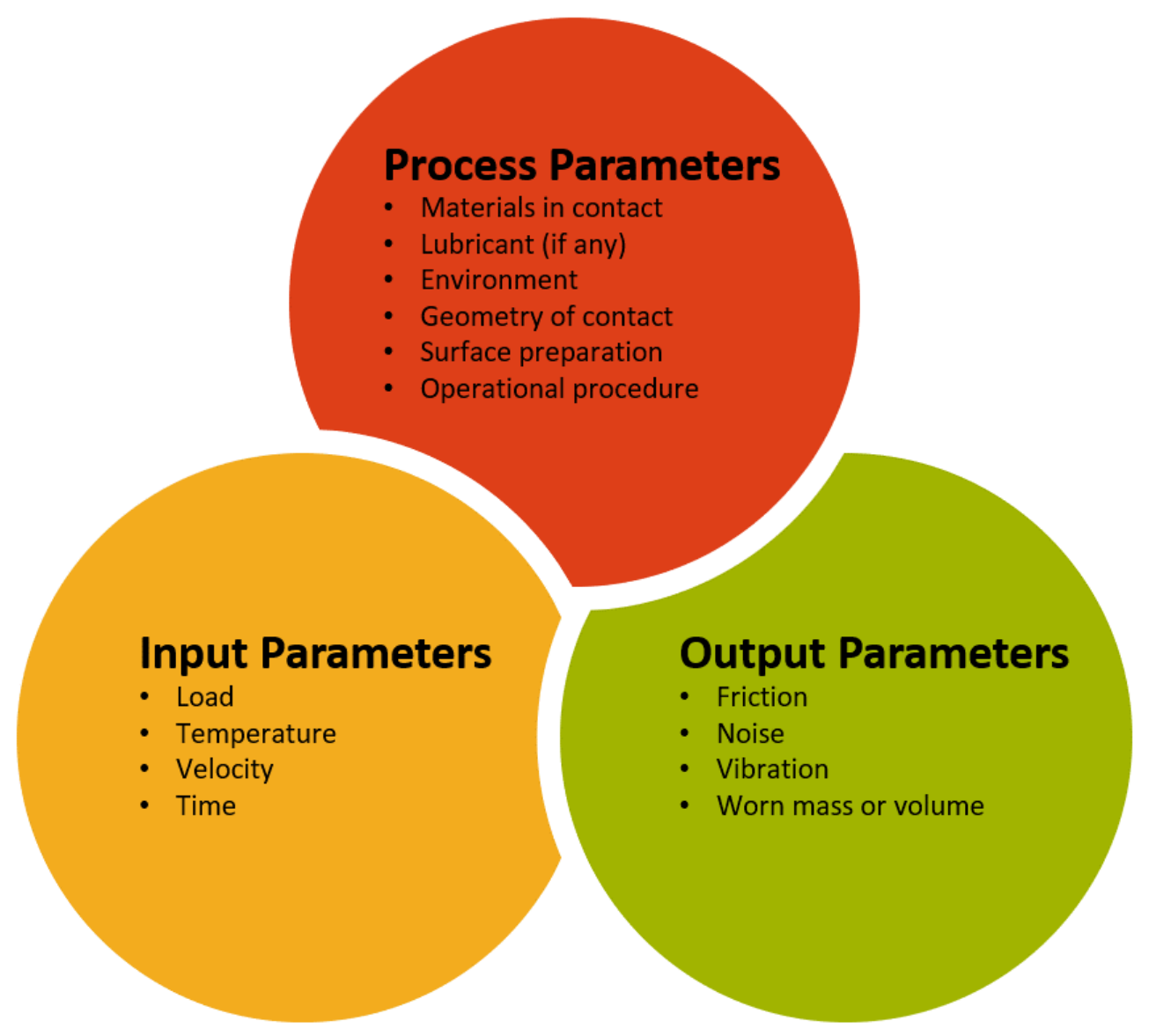

Figure 9. Schematic representing factors influencing the wear process.

Tribology is the branch of science that deals with friction and wear, concerning with interacting bodies with relative motion. Friction refers to the resistance to movement that occurs as a solid body moves tangentially across the surface of another body in contact with it. Friction is thus a system response in the form of a reaction force, rather than a material property. The process of material removal from moving surfaces in contact with each other is known as wear. Considering the mentioned explanations, it could be noted that both wear and friction are caused by the same tribological contact process [161].

A system's mechanics and kinematics characterize its wear process, which are classified by mechanisms such as abrasive, adhesive, fatigue, erosive, and tribo-chemical wear. The abrasive wear is typically observed in the sliding contacts (usually hard asperities) of two moving surfaces. This leads to plastic deformation or fracture, by which the softer surface gets damaged. According to the surface features and patterns formed on the tested specimens, some researchers have classified three different modes for abrasive wear; (i) wedge forming (wedge shaped debris), (ii) micro-cutting (curl-shaped ribbon debris), and (iii) ploughing (shallow grooves). Moreover, the formation of adhesive bonds in sliding contacts and the subsequent detachment and/or peeling of these bonds mark the adhesive wear [171].

\subsubsection{Friction-Wear Behavior at Ambient Temperatures}

The influence of introduction of $\mathrm{Al}_{2} \mathrm{O}_{3}$ to HVOF-sprayed NiCoCrAlY coatings was examined by Zhao et al. [48]. They pointed out that both strengthened and un-strengthened coatings showed similar wear rates under sliding test conditions; however, different worn surface of the coatings were observed. It was found that smaller debris were removed in the case of $\mathrm{Al}_{2} \mathrm{O}_{3}$-strengthened coating due to its finer microstructure. Weitong and Dejun [49] investigated the friction-wear behavior of laser-cladded $\mathrm{Al}_{2} \mathrm{O}_{3}$-reinforced CoCrAlYTaSi coatings. The results of their research indicated that the addition of $\mathrm{Al}_{2} \mathrm{O}_{3}-$ 
reinforcement with a mass fraction of $15 \%$ showed the best friction performance, resulting in an average COF of 0.17 , which was $85 \%$ lower than that of pure CoCrAlYTaSi coating. It was observed that the $\mathrm{CoO}, \mathrm{TaO}$, and $\mathrm{Al}_{2} \mathrm{O}_{3}$ oxides were present on the worn tracks, amongst which $\mathrm{Al}_{2} \mathrm{O}_{3}$ was the major component of debris and its lubrication effect reduced the COF and wear rate. Further, a study by Yanliang et al. [23] showed the influence of $\mathrm{Al}_{2} \mathrm{O}_{3}$ addition on the wear mechanism of CoCrAlYTa coatings applied by laser-induction hybrid cladding technique. In their research, it was found that the presence of alumina reinforcing particles caused an increase in the relatively hard $\beta$ phase of matrix, which led to surface hardening and effective resisting against the grinding ball. This changed the wear mechanism from severe adhesive wear, for the un-modified coating, to a typical micro-cutting condition with a lower wear rate.

In a study by Bolelli et al. [70], the sliding wear behavior of NiCrAlY coatings with and without alumina reinforcement $(3,6,12,18 \mathrm{wt}$.\%) was investigated. The wear mechanism of the as-sprayed NiCrAlY coating was adhesive wear at room temperature. Due to repeated surface plastic deformation and adherence of coating to the ball surface, extrusion of material lips and delamination were observed in some regions. The delamination could become worse due to microstructural defects in coating, such as inter-lamellar oxides. Following the wear test, the examination of detached fragments showed a platelet morphology, which is a typical debris feature in adhesive wear mechanism. On the other hand, the collected wear debris of $\mathrm{Al}_{2} \mathrm{O}_{3}$-reinforced coatings were quite distinct and were comprised of sub-micrometric oxidized particles. These features are indicative of the tribo-oxidation mechanism. Moreover, a tribo-layer was generated on the wear scar due to the smearing and compaction of debris. The growth of tribo-layer was promoted by the progressive fragmentation of alumina particles, by which they were pulled out of coating and then were smeared onto the coating surface. Accordingly, as the contact area between coating and counter body was intermediated by the formed tribo-layer, a low-wear condition was stabilized. Overall, the coating with $18 \mathrm{wt}$.\% exhibited the best performance, mainly due to the evolution of tribo-layer under the tribo-oxidation wear mechanism.

The influence of counter body hardness on the wear rate of WC-Co added NiCoCrA1YTa coatings was investigated in [91]. The results showed an increasing trend in wear resistance of coatings by increasing the WC-Co contents, which was mainly attributed to the increased hardness. The coatings were tested against two different balls, namely GCr15 steel (HV 851) and WC (HV 1641). The recorded friction coefficients were insensitive to the ball type; however, the wear rates of softer coatings were considerably higher in tests with WC ball, compared to the harder coatings which showed almost equal wear rates for both ball types. Moreover, Raman analysis of the worn surface of composite coatings revealed the formation of many oxide compounds. This was caused by the generation of instantaneous heat and stress during the wear-friction process, by which a series of tribo-chemical reactions were stimulated.

\subsection{Friction-Wear at Elevated Temperatures}

Although the experiments reported in the literature state specific temperature values for conducting friction-wear tests, it must be noted that the experiencing temperature at the contact surfaces is higher due to the generated friction heat [87][172]. Moreover, change in the mechanical properties of the materials at high temperatures must be taken into consideration. Generally, a rise in ductility is frequently caused by increasing temperature, which leads to a greater potential for plastic deformation [173].

\subsubsection{Important Factors for Temperature-Affected Friction-Wear}

Increasing surface temperatures of components during sliding contact may correspond to two factors: (i) frictional heating as a result of severe sliding conditions, namely high loads and speeds, and (ii) application of external heat. When encountering these conditions, oxidation of the metallic component initiates; consequently, causing a considerable effect on the overall wear rates and the extent of damage. Put differently, in addition 
to being subjected to the stresses due to the contact and friction forces, the surfaces are also susceptible to high-temperature oxidation during sliding. As a consequence, the wear mechanism may be influenced by the presence of oxide particles within wear debris and/or by the oxides formed on the surface.

Based on contact conditions and oxidation characteristics of the materials, different scenarios could be assumed for the generation of oxides and their effects during sliding. First, the sliding action can cause breaking up fine metallic particles in the form of wear debris wherein they get exposed to the oxidizing environment. Irrespective of the alloy composition, the oxidation process of metallic debris is relatively rapid owing to the large surface area to volume ratio, increased surface energies, and higher defect densities of these particles [174]. There are several ways by which these wear debris particles may affect the wear performance:

- The wear process would not be altered, if the debris particles get removed during sliding of components.

- If the debris particles remain between the contacting surfaces, then they may act either as two- or three-body abradants. The former occurs when the particles become embedded in one surface and the latter takes place when the particles get to move freely between the surfaces.

- In the non-moving state, the debris particles promote the formation of solid layers consisted of sintered particles, which can provide wear-protection.

Most of the high-temperature wear tests on the MCrAlY-based coatings report a tribo-oxidation mechanism, by which a tribo-layer termed as "glaze", uniformly covers the coating surface. Typically, the tribo-layer is developed by the oxidation of MCrAlY alloy inside the wear scar and consists of a dense oxide scale. It must be noted that the tribo-layer is much thicker and distinct from the thermally-grown oxide outside the wear scar [70]. The thickening of the glaze film is related to two simultaneously occurring mechanisms [175]:

1. The intensification of oxidation process due to the generation of high flash temperatures.

2. The development of lattice defects as a result of plastic deformation at the surface adjacent to the contact point. The developed defects promote oxygen diffusion, by which it accelerates the oxidation kinetics.

\subsubsection{Oxide Scale Formation on MCrAlY Alloys at High Temperatures}

In a large number of industrial applications, the components are subjected to working temperature variations, by which the coated parts are inevitably oxidized to develop surface oxide scales. Since the generation of these scales could affect the contact state of the mechanical components, special emphasis should be placed on their influence in the tribological studies. Subject to the favorable oxidation kinetics, these oxides (commonly known as "glazes") form throughout the sliding movement, which can significantly lower the total tribological damages [175]. Moreover, due to the differences in crystalline structure and chemistry of various oxides formed on the surface, it is expected that they would have distinct influences on the tribological behavior [169]. In this respect, a brief description of the high-temperature behavior of MCrAlY alloys is presented here.

From thermodynamic perspective, all high-temperature materials are unstable in air and they form oxides by reacting with oxygen. The MCrAlY alloys are no exception and they develop oxide scales to provide protection [176]. A preferable protective oxide would be expected to be slow-growing, adherent, and serve as a diffusion barrier to oxygen, so as to prevent further oxidation. It is well-known that the MCrAlY alloys are good aluminaformers; however, other types of oxides can also be formed, depending on the oxidation conditions, geometrical factors, and alloy compositions [177].

A large research effort has been spent on understanding the MCrAlY alloy oxidation, finding and validating models for describing the oxide growth kinetics. That being said, considering the complexity of these alloys, which adds to the number of possible 
outcomes, results in several oxidation modes with different reaction products. Given that the rate-controlling process in the growth of compact oxides is commonly the solid-state diffusion of charged ions $\left(\mathrm{M}^{\mathrm{n}+}\right.$ or $\left.\mathrm{O}^{2-}\right)$ through the developed oxide layer itself, a parabolic rate law is usually used for describing the high-temperature oxide growth of MCrAlY alloys. Table 5 lists some of the possible oxides for a typical MCrAlY alloy with the corresponding formation reactions and their standard Gibbs free energies at 900 and $1000{ }^{\circ} \mathrm{C}$.

Table 5. Probable oxides and their oxidation reactions with the corresponding Gibbs free energy of formation [169][178][179].

\begin{tabular}{cccc}
\hline Oxide & Reaction & $\Delta G_{900}{ }^{\circ} \mathrm{C}(\mathbf{k J} / \mathbf{m o l})$ & $\Delta \mathbf{G}_{\mathbf{1 0 0 0}}{ }^{\circ} \mathrm{C}(\mathbf{k J} / \mathbf{m o l})$ \\
\hline $\mathrm{NiO}$ & $\mathrm{Ni}_{(\mathrm{s})}+0.5 \mathrm{O}_{2(\mathrm{~g})}=\mathrm{NiO}_{(\mathrm{s})}$ & -275.8 & -256.9 \\
$\mathrm{CoO}$ & $\mathrm{Co}(\mathrm{s})+0.5 \mathrm{O}_{2(\mathrm{~g})}=\mathrm{CoO}_{(\mathrm{s})}$ & -353.8 & -343.4 \\
$\mathrm{Cr}_{2} \mathrm{O}_{3}$ & $2 \mathrm{Cr}_{(\mathrm{s})}+1.5 \mathrm{O}_{2(\mathrm{~g})}=\mathrm{Cr}_{2} \mathrm{O}_{3(\mathrm{~s})}$ & -538.9 & -520.7 \\
$\mathrm{Al}_{2} \mathrm{O}_{3}$ & $2 \mathrm{Al}_{(\mathrm{s})}+1.5 \mathrm{O}_{2(\mathrm{~g})}=\mathrm{Al}_{2} \mathrm{O}_{3(\mathrm{~s})}$ & -871.4 & -850.5 \\
$\mathrm{NiCr}_{2} \mathrm{O}_{4}$ & $\mathrm{NiO}_{(\mathrm{s})}+\mathrm{Cr}_{2} \mathrm{O}_{3}(\mathrm{~s})=\mathrm{NiCr}_{2} \mathrm{O}_{4}(\mathrm{~s})$ & -43.7 & -42.9 \\
$\mathrm{CoCr}_{2} \mathrm{O}_{4}$ & $\mathrm{CoO}_{(\mathrm{s})}+\mathrm{Cr}_{2} \mathrm{O}_{3(\mathrm{~s})}=\mathrm{CoCr}_{2} \mathrm{O}_{4}(\mathrm{~s})$ & -88.8 & -101.5 \\
$\mathrm{NiAl}_{2} \mathrm{O}_{4}$ & $\mathrm{NiO}_{(\mathrm{s})}+\mathrm{Al}_{2} \mathrm{O}_{3(\mathrm{~s})}=\mathrm{NiAl}_{2} \mathrm{O}_{4}(\mathrm{~s})$ & -109.3 & -115.4 \\
$\mathrm{CoAl} \mathrm{O}_{4}$ & $\mathrm{CoO}_{(\mathrm{s})}+\mathrm{Al}_{2} \mathrm{O}_{3(\mathrm{~s})}=\mathrm{CoAl}_{2} \mathrm{O}_{4}(\mathrm{~s})$ & -83.3 & -93.3 \\
\hline
\end{tabular}

\subsubsection{High-Temperature Friction-Wear Behavior}

In terms of the operating temperatures, sliding of the MCrAlY-based coatings can undergo different wear mechanisms. This is mainly rooted in the formation of oxide layers, as the surface gets exposed to high temperatures, which in turn affects the coatings' tribological behavior. In addition to the oxide layers, other types of chemically-reacted layers such as chlorides, nitrides, and sulfides can also form, depending on the environment. Overall, the formation of surface layers depends upon the temperature and time of reaction together with the material's reactivity to the environment. With this in mind, it is crucial to take into account the chemistry and dimension of the different surface layers, when considering the tribological performance at elevated temperatures.

Hou et al. [50] evaluated the friction and wear performance of $\mathrm{CoCrAlYTaCSi}-\mathrm{Al}_{2} \mathrm{O}_{3}$ composite coating deposited by HVOF spraying. They reported that under dry sliding at $1000{ }^{\circ} \mathrm{C}$, the composite coating exhibited low COF $(\sim 0.25)$ and improved wear resistance, which the former has been attributed to the self-lubricity of the coatings as a result of the formed glazed layers, and the latter has been explained by the increased hardness along with the enhanced mechanical properties due to the $\mathrm{Al}_{2} \mathrm{O}_{3}$ dispersion strengthening. In another work [51], the investigation of laser cladded NiCoCrAlY coatings strengthened with $\mathrm{Al}_{2} \mathrm{O}_{3}, \mathrm{SiC}$, and $\mathrm{CeO}_{2}$ showed an improved high-temperature wear resistance and increased hardness as well. Among the different reinforcing materials, the incorporation of $\mathrm{SiC}$ had the most prominent effect on reducing the wear rate at $500{ }^{\circ} \mathrm{C}$, which was $34 \%$ of that of conventional NiCoCrAlY coating. This was in accordance with the highest hardness achieved by the addition of $\mathrm{SiC}$, which indicated the significant role of coating hardness in its wear performance. Moreover, some microstructural factors, including the single dispersion of $\mathrm{SiC}$ particles instead of micro-aggregates and having good stability during the laser cladding process, assisted the wear resistance. Moreover, evaluation of the addition of a combination of $\mathrm{Al}_{2} \mathrm{O}_{3}$ and $\mathrm{Cr}_{2} \mathrm{O}_{3}$ as reinforcing materials for improving the frictional wear properties of APS-sprayed NiCoCrAlY coating was reported in [53]. It was noted that under non-lubrication sliding condition at $500{ }^{\circ} \mathrm{C}$, the coating effectively protected the substrate, and it showed a significantly lower mass loss, which was $1 / 15$ of the substrate.

The formation of oxide scales at high temperatures must be considered in the evaluation of coatings' wear performance. A study on the high-temperature frictional wear properties of laser-cladded $\mathrm{NiCoCrAlY}$ with $\mathrm{Al}_{2} \mathrm{O}_{3}$ reinforcement showed that at $500{ }^{\circ} \mathrm{C}$, the formed oxide scale on the coating surface replaced the coating material in terms of being in contact with the counterpart; therefore, the characteristics of the oxide scale 
determined the wear rate [97]. In this condition, formation of a dense oxide scale in shorter times translates into higher wear resistance. Moreover, Picas et al. [67] explored the tribological properties of HVOF-sprayed $\mathrm{Cr}_{3} \mathrm{C}_{2}-\mathrm{CoNiCrAlY}$ coatings and found out that the heat-treatment at $900-1100{ }^{\circ} \mathrm{C}$ range caused an increase in the surface hardness of the coating, which provided smaller wear rates due to the formation of $\mathrm{Cr}_{2} \mathrm{O}_{3}$ during the oxidation of $\mathrm{Cr}_{3} \mathrm{C}_{2}$ reinforcement particles.

Investigation due to Ref [92] further confirmed the role of oxide chemistry in wear resistance. In this study, the incorporation of $\mathrm{CeO}_{2}$ reinforcement to the laser-cladded $\mathrm{NiCoCrAlY}$ coatings has elevated their wear resistance at $600{ }^{\circ} \mathrm{C}$. Examination of worn tracks revealed that more oxides were ejected during the experiments with unmodified coatings, which led to scratching of the coating and caused abrasive wear. In addition, the loading force and high-temperature provided a condition, in which a welding junction was formed between the tribo-pair and resulted in adhesive wear. On the other hand, addition of $\mathrm{CeO}_{2}$ reduced the damage due to oxidation wear mechanism and a small number of fallen oxide particles were evident. Further, a study by Wei et al. [87] clarified the superior resistance of reinforced MCrAlY coating in high-temperature friction-wear tests. In their research, $\mathrm{CoCrAlYTa}-10 \% \mathrm{Al}_{2} \mathrm{O}_{3}$ coatings were deposited by $\mathrm{HVOF}$ technique, and their wear properties were examined through conducting ball-on-disk sliding experiments at $25-600{ }^{\circ} \mathrm{C}$ temperature range. When the testing temperature increased, the results reveled significantly lower wear rates in the case of coated samples, as opposed to the uncoated H13 steel substrates. The principal reason for the higher wear resistance, as well as the lower COF, of the coated samples was related to the formation of continuous, compact, and smooth tribo-films at elevated temperatures. Not only did the formation of tribo-films promote antifriction effect, but it also increased the microhardness and reduced the cutting effect associated with the abrasive wear.

\subsection{Erosion Performance}

The material loss due to repeatedly striking particles is referred to as solid particle erosion (SPE). This phenomenon can occur in gaseous or liquid media containing flowing particles, and it results in mass change due to material removal or particle sticking to the surface [6]. Moreover, great number of industries are being affected by this degrading process, such as the equipment used in petrochemical and mining, as well as gas turbine operation in sandy environments. Oftentimes, the material degradation caused by SPE is manifested as rough surface with signs of cutting and pinholes. The benefits of erosion protection are huge; both technical (e.g., improved efficiency) and economic (e.g., reduced maintenance expenses) [180]. Therefore, studies on enhanced protective coatings are required to counteract erosion damage. This section provides the erosion behavior of MCrAlY-based coatings together with the corresponding mechanism and key affecting parameters.

\subsubsection{Important Factors for Erosion}

It is clear that preventing erosion damage and increasing the reliability and longevity of coated components lies in the thorough understanding of damage mechanisms. In comparison with the bulk materials, investigating the mechanism of SPE for coated samples can get highly complex. Various parameters are involved in the tests and there are correlations between them and the investigated material's behavior. This may activate two or more erosion mechanisms, causing different results to be interpreted. Some of the most critical particle characteristics that influence the erosion behavior include size, shape, strength, and hardness. Besides, surface properties of the specimen, such as hardness, fracture toughness, microstructure, residual stress, and oxidation resistance can have a major impact on the erosion performance [181].

There is a distinct difference between the erosion rate of metals, as ductile materials, and ceramics, as brittle materials. Findings have shown that at angles near $90^{\circ}$ ceramics display the highest erosion rate, and the maximum erosion rate for metals are recorded at 
angles near $30^{\circ}$. This has been shown for the APS-sprayed NiCrAlY and NiCoCrAlY coatings, which had the highest erosion rate at $30^{\circ}$ impact angle [182]. Moreover, using sharp abrasive particles at increased impact velocities cause more surface damage than those of spherical particles with less kinetic energy. It must be noted that in recent erosion theories, parameters such as Young's modulus (E), hardness (H), fracture toughness (KIC), and indentation modulus (Етт) are all considered as important materials properties in determining erosion behavior. Overall, having a low EIT, high $\mathrm{H}$, and a high $\mathrm{K}_{\mathrm{IC}}$ are the favorable characteristics of a good candidate for SPE resistance [183]. Furthermore, characterizing the nature of dominant mechanism in erosion processes can be indicated by erosion efficiency $(\eta)$ parameter [184]:

$$
\eta=\frac{2 E H}{\rho V^{2}} \times 100
$$

In which $\mathrm{E}, \mathrm{H}$, and $\mathrm{Q}$ denote the erosion rate, hardness, and density of the sample, respectively and $\mathrm{V}$ being the impact velocity. Determining the erosion efficiency reveals the ductile or brittle response of the tested material. When the micro-ploughing is the only dominant mechanism, no fracture or erosion takes place, and the $\eta$ will be zero. On the other side, micro-cutting controlled process is when the $\eta$ will be $100 \%$. The erosion efficiency of MCrAlY-based coatings, as ductile metallic materials, is expected to be in between of this range.

\subsubsection{Erosion Behavior at Ambient Temperatures}

A common form of failure for the engineering systems associated with the solid particle/solid surface mechanical interactions is due to the solid particle erosion (SPE) phenomenon. This process can be observed as the progressive loss of original material in various systems, including transportation pipelines and valves as well as steam and gas turbines, all of which are operating in environments where the ingestion of solid particles cannot be fully avoided [185][186].

In a study [187], the SPE behavior of HVOF-sprayed NiCrAlY coating reinforced with $\mathrm{Cr}_{3} \mathrm{C}_{2}$ was investigated at impact angles of $30^{\circ}, 60^{\circ}$, and $90^{\circ}$. The composite coating exhibited a mixed mode of erosion damage, where it had the highest erosion rate at impact angle of $60^{\circ}$. The interesting finding of this research was the lower volume erosion rate of the Ti-6Al-4V substrate compared to the coated samples at steady state. This was attributed to the huge difference between the hardness values of substrate and silica as the erodent particles, which led to the penetration of silica particles into the substrate surface; therefore, providing shielding effect against the subsequent impacts. Moreover, other factors including the ability to plastic deformation as well as strain hardening played a role in lowering the erosion rate.

\subsection{Erosion Performance at Elevated Temperatures}

At high temperatures, solid particle erosion degrades multiple industrial systems. The interplay between erosion and oxidation is the critical and determining factor in SPE mechanism. Considering this, it is evident that reaching a suitable SPE resistance for a material demands good mechanical properties at elevated temperatures, as well as the ability to form oxidation-resistant and adherent scale. From the numerous studies reported in the literature it is evident that the MCrAlY coatings are good alumina formers which favors the high erosion resistance; thus, the enhanced tribological and mechanical properties should be provided by the addition of reinforcements [180].

\subsubsection{Important Factors for Temperature-Affected Erosion}

Low-temperature erosion in a corrosive medium is typically referred to as erosioncorrosion, whereas high-temperature erosion is more commonly known as erosion-oxidation. Nevertheless, there is no distinct temperature range distinguishing these two phenomena, which is likely due to the differences in oxidation responses of materials at various temperatures [188]. It is to be noted that both phenomena are complex; hence, 
knowing the precise performance of components demand simulated conditions to carry out the tests.

Similar to the erosion investigations at ambient temperatures, testing parameters such as erodent type, velocity, and impingement angle have significant effects on materials' response. Another major variant at the elevated temperatures is the characteristics of the pre-formed oxide scale, which might be removed partially or completely depending on the aforementioned parameters. Provided that a single-phase layer uniformly covers the coating surface, then the erosion behavior is proportional to the layer thickness removal per impact. In addition, the regrowth rate of this layer plays a key role in maintaining the protection, which is predominantly governed by the temperature and its kinetics. As can be understood, due to complex relationships being involved in erosion-oxidation processes, determining the exact mechanisms is extremely challenging [189].

\subsubsection{High-Temperature Erosion Behavior}

Another failure mechanism threatening the performance of components that are subjected to combined oxidation attack and erosion conditions is known as high-temperature solid particle erosion. The corrosion phenomenon at higher temperatures can pose a great risk on the durability and dimensional stability of the components used in applications where tribological contact is a determinant for their service life. With this in mind, serious efforts have been in figuring out the root cause of the failures dealing with erosion at elevated temperatures and improving the coatings' erosion performance.

Mathapati et al. [190] studied the erosion behavior of plasma-sprayed NiCrAlY/WC$\mathrm{Co} /$ Cenosphere coating on a MDN 321 steel substrate at the temperature values of 200, 400 , and $600{ }^{\circ} \mathrm{C}$. They have reported that the coating deposition increased the high-temperature erosion resistance of the specimen by $71 \%$ compared to the uncoated substrate. This study revealed that the improved erosion resistance of the coating was considerable when the evaluations were conducted at $30^{\circ}$ impact angle rather than $90^{\circ}$. The deteriorated erosion performance at higher impact angles was attributed to the brittle erosive mechanism of the coating, wherein crack formation and chipping caused material removal. Further, a research work conducted by Nithin et al. [55] reported the superior effect of WC$\mathrm{Co}$, in comparison with $\mathrm{NiCr}-\mathrm{Cr}_{3} \mathrm{C}_{2}$, in enhancing the resistance of APS-sprayed CoCrAlY coating against solid particle erosion at $600{ }^{\circ} \mathrm{C}$. The authors found severe erosion loss and more brittle fractures in the case of $\mathrm{NiCr}-\mathrm{Cr}_{3} \mathrm{C}_{2}$-strengthened coating and suggested that the lower melting point of $\mathrm{Cr}_{3} \mathrm{C}_{2}$ caused its dissolution within the binder, which in turn, resulted in the embrittlement of coating.

Due to the desirable properties of alumina and ceria, such as high hardness and good thermal stability, they were chosen as reinforcements in a CoCrAlY matrix [74]. The conducted SPE studies at $600{ }^{\circ} \mathrm{C}$ showed a remarkable improvement in the erosion behavior of coated samples, as opposed to the bare Ni-based superalloy, which exhibited large variations in the erosion rate. Further, the authors report that the oxidation of coatings during the initial stages of tests led to the development of protective oxides acting as barriers to the impingement of the erodent particles. Also, the measured erosion depth of coatings indicated their effectiveness in preventing the penetration of erodent particles. Moreover, both coatings showed higher erosion rates at low impact angle $\left(30^{\circ}\right)$, in which severe plowing marks, as well as microcutting and craters, were found on the eroded surfaces. Overall, the erosion rate of both coatings was followed by the oxidation-modified behavior, with $\mathrm{CeO}_{2}$-added coating being more resistant to SPE, showing 50\% less volume loss. 


\section{Concluding Remarks and Future Perspectives}

The incorporation of hard particles into the MCrAlY-based coatings has broaden their successful applications in the protection of engineering structural materials exposed to tribological damage, especially at high temperatures. In favor of the tailored property combinations, like the protection of matrix and the high strength of reinforcements, these coatings can satisfy the current needs for most of the components operating in demanding environments. Indeed, the new capabilities provided by these coatings would benefit a number of industries such as aerospace, automobile, marine, and chemical. Nevertheless, there is much room for future research areas in improving the performance of reinforced MCrAlY coatings.

In some studies, researchers are coming up with a novel matrix for coating composition and exploring its wear resistance in the room temperature as well as elevated temperature tests. Derelizade et al. [191] used a recently developed CrNiAlCY alloy for coating deposition via HVOF spraying. The ultimate objective was to benefit from the combined positive effects of $\mathrm{CrC}$ and $\mathrm{NiAl}$ phases in improving the matrix strength together with its corrosion and wear resistance. The conducted wear tests at $900{ }^{\circ} \mathrm{C}$ exhibited no signs of carbide decarburization in the coating microstructure and the formation of a protective chromia layer kept the surface from deteriorating, up to $30 \mathrm{~N}$ of applied load. These findings suggest a promising material for high-temperature applications, and it can be further enhanced by the proper addition of reinforcement(s).

Throughout this review, the majority of tribological approaches to investigate the coating performance were analytical and experimental studies. Nowadays, the numerical simulation methods are showing great potential in contributing to expand the horizon of mechanistic understanding in failure mechanisms of tribological systems. It should be noted that the successful development of multiphysics and multiscale models require multidisciplinary expertise, including materials science, chemistry, physics, and solid mechanics [192]. Therefore, conducting interdisciplinary research with the use of computational investigation techniques could give new insights into the tribological behavior of MCrAlY-based coatings.

Funding: This research received no external funding.

Conflicts of Interest: The authors declare no conflict of interest.

\section{References}

1. [1] J.R. Davis, Surface engineering for corrosion and wear resistance, ASM international, 2001.

2. [2] T.M. Pollock, S. Tin, Nickel-based superalloys for advanced turbine engines: Chemistry, microstructure, and properties, J. Propuls. Power. 22 (2006) 361-374. https://doi.org/10.2514/1.18239.

[3] T.N. Rhys-Jones, Coatings for blade and vane applications in gas turbines, Corros. Sci. 29 (1989) $623-646$.

[4] R. Rajendran, Gas turbine coatings-An overview, Eng. Fail. Anal. 26 (2012) 355-369.

[5] F. Cernuschi, C. Guardamagna, S. Capelli, L. Lorenzoni, D.E. Mack, A. Moscatelli, Solid particle erosion of standard and advanced thermal barrier coatings, Wear. 348 (2016) 43-51.

6. [6] O. Gohardani, Impact of erosion testing aspects on current and future flight conditions, Prog. Aerosp. Sci. 47 (2011) 280303. https://doi.org/10.1016/j.paerosci.2011.04.001.

7. [7] K. Miyoshi, Solid lubricants and coatings for extreme environments: state-of-the-art survey, (2007).

8. [8] K. Radil, C. DellaCorte, The Performance of PS400 Subjected to Sliding Contact at Temperatures from 260 to $927^{\circ} \mathrm{C}$, Tribol. Trans. 60 (2017) 957-964. https://doi.org/10.1080/10402004.2016.1231357.

9. [9] G. Bolelli, C. Vorkötter, L. Lusvarghi, S. Morelli, V. Testa, R. Vaßen, Performance of wear resistant MCrAlY coatings with oxide dispersion strengthening, Wear. 444-445 (2020) 203116. https://doi.org/10.1016/j.wear.2019.203116.

10. [10] S. Hong, Y. Wu, B. Wang, J. Zhang, Y. Zheng, L. Qiao, The effect of temperature on the dry sliding wear behavior of HVOF sprayed nanostructured WC-CoCr coatings, Ceram. Int. 43 (2017) 458-462. https://doi.org/10.1016/j.ceramint.2016.09.180.

11. [11] T. Wang, F. Ye, The elevated-temperature wear behavior evolution of HVOF sprayed tungsten carbide coatings: Respond to heat treatment, Int. J. Refract. Met. Hard Mater. 71 (2018) 92-100. https://doi.org/10.1016/j.ijrmhm.2017.11.007.

12. [12] P. Mi, H. Zhao, T. Wang, F. Ye, Sliding wear behavior of HVOF sprayed WC-(nano-WC-Co) coating at elevated temperatures, Mater. Chem. Phys. 206 (2018) 1-6. https://doi.org/10.1016/j.matchemphys.2017.09.066. 
13. [13] P. Mi, T. Wang, F. Ye, Influences of the compositions and mechanical properties of HVOF sprayed bimodal WC-Co coating on its high temperature wear performance, Int. J. Refract. Met. Hard Mater. 69 (2017) 158-163. https://doi.org/10.1016/j.ijrmhm.2017.08.012.

14. [14] V. Bonache, M.D. Salvador, J.C. García, E. Sánchez, E. Bannier, Influence of plasma intensity on wear and erosion resistance of conventional and nanometric WC-Co coatings deposited by APS, J. Therm. Spray Technol. 20 (2011) 549-559. https://doi.org/10.1007/s11666-010-9572-2.

15. [15] Z. Geng, S. Hou, G. Shi, D. Duan, S. Li, Tribological behaviour at various temperatures of WC-Co coatings prepared using different thermal spraying techniques, Tribol. Int. 104 (2016) 36-44. https://doi.org/10.1016/j.triboint.2016.08.025.

16. [16] K. Szymański, A. Hernas, G. Moskal, H. Myalska, Thermally sprayed coatings resistant to erosion and corrosion for power plant boilers - A review, Surf. Coatings Technol. 268 (2015) 153-164. https://doi.org/10.1016/j.surfcoat.2014.10.046.

17. [17] L.M. Berger, Application of hardmetals as thermal spray coatings, Int. J. Refract. Met. Hard Mater. 49 (2015) $350-364$. https://doi.org/10.1016/j.ijrmhm.2014.09.029.

18. [18] J. García, V. Collado Ciprés, A. Blomqvist, B. Kaplan, Cemented carbide microstructures: a review, Int. J. Refract. Met. Hard Mater. 80 (2019) 40-68. https://doi.org/10.1016/j.ijrmhm.2018.12.004.

19. [19] B.H. Kear, G. Skandan, R.K. Sadangi, Factors controlling decarburization in HVOF sprayed nano-WC/Co hardcoatings, Scr. Mater. 44 (2001) 1703-1707. https://doi.org/10.1016/S1359-6462(01)00867-3.

20. [20] P.H. Shipway, D.G. McCartney, T. Sudaprasert, Sliding wear behaviour of conventional and nanostructured HVOF sprayed WC-Co coatings, Wear. 259 (2005) 820-827. https://doi.org/10.1016/j.wear.2005.02.059.

21. [21] V.A.D. Souza, A. Neville, Corrosion and synergy in a WC-Co-Cr HVOF thermal spray coating - Understanding their role in erosion-corrosion degradation, Wear. 259 (2005) 171-180. https://doi.org/10.1016/j.wear.2004.12.003.

22. [22] Z. Esmaeili, M.R. Loghman-Estarki, M. Ramezani, M. Naderi, E. Mohammad Sharifi, Toward hardening of NiCrAlY alloy by spark plasma sintering of NiCrAlY-nanoSi3N4-graphite nanocomposite, J. Alloys Compd. 847 (2020) 155802. https://doi.org/10.1016/j.jallcom.2020.155802.

23. [23] Y. Yanliang, L. Shaolei, Z. Rui, W. Changyi, Z. Shengfeng, Influence of Al2O3 particles on the tribological properties of CoCrAlYTa coating produced by laser-induction hybrid cladding, Ceram. Int. (2021). https://doi.org/10.1016/j.ceramint.2021.03.280.

24. [24] A. Feuerstein, J. Knapp, T. Taylor, A. Ashary, A. Bolcavage, N. Hitchman, Technical and economical aspects of current thermal barrier coating systems for gas turbine engines by thermal spray and EBPVD: a review, J. Therm. Spray Technol. 17 (2008) 199-213.

25. [25] A. Zakeri, M.R. Masoumi Balashadehi, A. Sabour Rouh Aghdam, Development of hybrid electrodeposition/slurry diffusion aluminide coatings on Ni-based superalloy with enhanced hot corrosion resistance, J. Compos. Compd. 2 (2021) 1-8. https://doi.org/10.52547/jcc.3.1.1.

26. [26] J.R. Nicholls, Designing oxidation-resistant coatings, JoM. 52 (2000) 28-35.

27. [27] W.G. Sloof, T.J. Nijdam, On the high-temperature oxidation of MCrAlY coatings, Int. J. Mater. Res. 100 (2009) 1318-1330. https://doi.org/10.3139/146.110201.

28. [28] P. Zhang, Performance of MCrAlX coatings: Oxidation, Hot corrosion and Interdiffusion, Linköping University Electronic Press, 2019. http://urn.kb.se/resolve?urn=urn:nbn:se:liu:diva161511\%0Ahttps://drive.google.com/open?id=1kM3K87i3iHHeYjStfnAi3OaS8QCMSQi4.

29. [29] C.S. Giggins, F.S. Pettit, Oxidation of Ni-Cr-Al Alloys Between $1000^{\circ}$ and $1200^{\circ}$ C, J. Electrochem. Soc. 118 (1971) 1782. https://doi.org/10.1149/1.2407837.

30. [30] M.J. Pomeroy, Coatings for gas turbine materials and long term stability issues, Mater. Des. 26 (2005) $223-231$. https://doi.org/10.1016/j.matdes.2004.02.005.

31. [31] S. Bose, High Temperature Coatings, Butterworth-Heinemann, 2007. https://doi.org/10.1016/B978-0-7506-8252-7.X50008.

32. [32] W. Brandl, D. Toma, H.J. Grabke, The characteristics of alumina scales formed on HVOF-sprayed MCrAlY coatings, Surf. Coatings Technol. 108-109 (1998) 10-15. https://doi.org/10.1016/S0257-8972(98)00613-6.

33. [33] Anon, Protective coatings for turbine components, ASM international, 1990.

34. [34] D. Naumenko, V. Shemet, L. Singheiser, W.J. Quadakkers, Failure mechanisms of thermal barrier coatings on MCrAlYtype bondcoats associated with the formation of the thermally grown oxide, J. Mater. Sci. 44 (2009) 1687-1703. https://doi.org/10.1007/s10853-009-3284-3.

35. [35] A. Zakeri, E. Bahmani, A. Sabour Rouh Aghdam, B. Saeedi, M. Bai, A study on the effect of nano-CeO2 dispersion on the characteristics of thermally-grown oxide (TGO) formed on NiCoCrAlY powders and coatings during isothermal oxidation, J. Alloys Compd. 835 (2020) 155319. https://doi.org/10.1016/j.jallcom.2020.155319.

36. [36] S. Zhang, D. Sun, Y. Fu, H. Du, Recent advances of superhard nanocomposite coatings: A review, Surf. Coatings Technol. 167 (2003) 113-119. https://doi.org/10.1016/S0257-8972(02)00903-9.

37. [37] C. Suryanarayana, N. Al-Aqeeli, Mechanically alloyed nanocomposites, Prog. Mater. Sci. 58 (2013) $383-502$. https://doi.org/10.1016/j.pmatsci.2012.10.001.

38. [38] L. He, M. Hassani, A Review of the Mechanical and Tribological Behavior of Cold Spray Metal Matrix Composites, J. Therm. Spray Technol. 29 (2020) 1565-1608. https://doi.org/10.1007/s11666-020-01091-w. 
39. [39] M. Hatami, F. Naeimi, M. Shamanian, M. Tahari, High-Temperature Oxidation Behavior of Nano-structured CoNiCrAlY-YSZ Coatings Produced by HVOF Thermal Spray Technique, Oxid. Met. 90 (2018) $153-167$. https://doi.org/10.1007/s11085-017-9829-y.

40. [40] C.W.K. D. Benjamin, Properties and selection: Stainless steels, Tool Materials and Special Purpose Metals, ASM International, Ohio, 1980, American Society for Metals, 2001. http://books.google.com.hk/books?id=eC-Zt1J4oCgC.

41. [41] W.F. Gale, T.C. Totemeier, Smithells Metals Reference Book (8th Edition), Elsevier. (2004).

42. [42] W.G. Fahrenholtz, G.E. Hilmas, I.G. Talmy, J.A. Zaykoski, Refractory diborides of zirconium and hafnium, J. Am. Ceram. Soc. 90 (2007) 1347-1364. https://doi.org/10.1111/j.1551-2916.2007.01583.x.

43. [43] H. Liu, H.R.S. Jazi, M. Bussmann, J. Mostaghimi, Experiments and modeling of rapid solidification of plasma-sprayed yttria-stabilized zirconia, Acta Mater. 57 (2009) 6013-6021. https://doi.org/10.1016/j.actamat.2009.08.023.

44. [44] U. Anselmi-Tamburini, J.N. Woolman, Z.A. Munir, Transparent nanometric cubic and tetragonal zirconia obtained by high-pressure pulsed electric current sintering, Adv. Funct. Mater. 17 (2007) 3267-3273. https://doi.org/10.1002/adfm.200600959.

45. [45] D. Sciti, S. Guicciardi, M. Nygren, Densification and mechanical behavior of HfC and HfB2 fabricated by spark plasma sintering, J. Am. Ceram. Soc. 91 (2008) 1433-1440. https://doi.org/10.1111/j.1551-2916.2007.02248.x.

46. [46] L. Pawlowski, The Science and Engineering of Thermal Spray Coatings: Second Edition, John Wiley \& Sons, 2008. https://doi.org/10.1002/9780470754085.

47. [47] B. Saeedi, A. Sabour Rouh Aghdam, G. Gholami, A study on nanostructured in-situ oxide dispersed NiAl coating and its high temperature oxidation behavior, Surf. Coatings Technol. 276 (2015) 704-713. https://doi.org/10.1016/j.surfcoat.2015.05.042.

48. [48] L. Zhao, M. Parco, E. Lugscheider, Wear behaviour of Al2O3 dispersion strengthened MCrAlY coating, Surf. Coatings Technol. 184 (2004) 298-306. https://doi.org/10.1016/j.surfcoat.2003.10.055.

49. [49] Z. Weitong, K. Dejun, Influence of Al2O3 mass fractions on microstructure, oxidation resistance and friction-wear behaviors of CoCrAlYTaSi coatings, Surf. Coatings Technol. 379 (2019) 125058. https://doi.org/10.1016/j.surfcoat.2019.125058.

50. [50] G. Hou, Y. An, X. Zhao, H. Zhou, J. Chen, Effect of alumina dispersion on oxidation behavior as well as friction and wear behavior of HVOF-sprayed CoCrAlYTaCSi coating at elevated temperature up to $1000{ }^{\circ} \mathrm{C}$, Acta Mater. 95 (2015) $164-175$. https://doi.org/10.1016/j.actamat.2015.05.025.

51. [51] H.Y. Wang, D.W. Zuo, M. Di Wang, G.F. Sun, H. Miao, Y.L. Sun, High temperature frictional wear behaviors of nanoparticle reinforced NiCoCrAlY cladded coatings, Trans. Nonferrous Met. Soc. China (English Ed. 21 (2011) $1322-1328$. https://doi.org/10.1016/S1003-6326(11)60860-1.

52. [52] Y. Cao, C. Huang, W. Liu, W. Zhang, L. Du, Effects of boron carbide content on the microstructure and properties of atmospheric plasma-sprayed NiCoCrAlY/Al2O3-B4C composite coatings, J. Therm. Spray Technol. 23 (2014) 716-724. https://doi.org/10.1007/s11666-014-0061-x.

53. [53] C. Tao, L. Wang, X. Song, High-temperature frictional wear behavior of MCrAlY-based coatings deposited by atmosphere plasma spraying, Int. J. Miner. Metall. Mater. 24 (2017) 222-228. https://doi.org/10.1007/s12613-017-1399-0.

54. [54] H.S. Nithin, K.M. Nishchitha, V. Shamanth, K. Hemanth, K.A. Babu, High-Temperature Oxidation and Corrosion Behaviour of APS CoCrAlY + $\mathrm{Cr} 3 \mathrm{C} 2-\mathrm{NiCr}$ Composite Coating, J. Bio- Tribo-Corrosion. 6 (2020) 1-11. https://doi.org/10.1007/s40735-020-0322-9.

55. [55] H.S. Nithin, V. Desai, M.R. Ramesh, Elevated temperature solid particle erosion behaviour of carbide reinforced CoCrAlY composite coatings, Mater. Res. Express. 5 (2018) 66529. https://doi.org/10.1088/2053-1591/aac998.

56. [56] P. Shi, W. Wang, S. Wan, Q. Gao, H. Sun, X. Feng, G. Yi, E. Xie, Q. Wang, Tribological performance and high temperature oxidation behaviour of thermal sprayed Ni- and NiCrAlY-based composite coatings, Surf. Coatings Technol. 405 (2021) 126615. https://doi.org/10.1016/j.surfcoat.2020.126615.

57. [57] Y. jiang Xie, M. cai Wang, A feasibility study of preparing MCrAlX/BN composite coatings by electrospark deposition process, J. Alloys Compd. 484 (2009) 21-24. https://doi.org/10.1016/j.jallcom.2009.05.017.

58. [58] M. Tahari, M. Shamanian, M. Salehi, The effect of heat treatment and thermal spray processes on the grain growth of nanostructured composite CoNiCrAlY/YSZ powders, J. Alloys Compd. 646 (2015) 372-379. https://doi.org/10.1016/j.jallcom.2015.06.020.

59. [59] D. Wang, W. Wang, M. Wang, Y. Li, X. Chen, C. Chi, Y. Xie, Effect of operating voltage on microstructure and microhardness of NiCoCrAlYTa-Y2O3 composite coatings on single crystal superalloy produced by electrospark deposition, Surf. Coatings Technol. 358 (2019) 628-636. https://doi.org/10.1016/j.surfcoat.2018.11.066.

60. [60] H. Peng, H. Guo, J. He, S. Gong, Cyclic oxidation and diffusion barrier behaviors of oxides dispersed NiCoCrAlY coatings, J. Alloys Compd. 502 (2010) 411-416. https://doi.org/10.1016/j.jallcom.2010.04.183.

61. [61] D. Wang, J. Gao, R. Zhang, S. Deng, S. Jiang, D. Cheng, P. Liu, Z. Xiong, W. Wang, Effect of TaC particles on the microstructure and oxidation behavior of NiCoCrAlYTa coating prepared by electrospark deposition on single crystal superalloy, Surf. Coatings Technol. 408 (2021) 126851. https://doi.org/10.1016/j.surfcoat.2021.126851.

62. [62] H. Wang, Y. Liu, X. Ning, Q. Wang, F. Wang, D. Chen, The influence of milling parameters on the characteristics of milled and spray-dried NiCoCrAlY-Al2O3 composite powders, Powder Metall. 60 (2017) 15-21. https://doi.org/10.1080/00325899.2016.1264683.

63. [63] C. Demian, A. Denoirjean, L. Pawłowski, P. Denoirjean, R. El Ouardi, Microstructural investigations of NiCrAlY + Y2O3 stabilized ZrO2 cermet coatings deposited by plasma transferred arc (PTA), Surf. Coatings Technol. 300 (2016) 104-109. https://doi.org/10.1016/j.surfcoat.2016.05.046. 
64. [64] H. yu WANG, D. wen ZUO, Y. li SUN, F. XU, D. ZHANG, Microstructure of nanometer Al2O3 dispersion strengthened Ni-based high-temperature protective coatings by laser cladding, Trans. Nonferrous Met. Soc. China (English Ed. 19 (2009) 586591. https://doi.org/10.1016/S1003-6326(08)60317-9.

65. [65] C. Guo, J. Chen, R. Yao, J. Zhou, Microstructure and high temperature wear resistance of laser cladding NiCoCrAlY/ZrB2 coating, Xiyou Jinshu Cailiao Yu Gongcheng/Rare Met. Mater. Eng. 42 (2013) 1547-1551. https://doi.org/10.1016/s1875-5372(13)60087-9.

66. [66] Z.-X. Hu, J.-R. Liu, C. Guo, J.-S. Zhou, S.-T. Zhang, Microstructure and Wear Resistance of Laser Cladding NiCoCrAlY/HfB (2) Coating at Elevated Temperature, Zhingguo Biaomian Gongcheng(China Surf. Eng. 25 (2012) 69-74.

67. [67] J.A. Picas, M. Punset, S. Menargues, E. Martín, M.T. Baile, Microstructural and tribological studies of as-sprayed and heat-treated HVOF Cr3C2-CoNiCrAlY coatings with a CoNiCrAlY bond coat, Surf. Coatings Technol. 268 (2015) $317-324$. https://doi.org/10.1016/j.surfcoat.2014.10.039.

68. [68] L. Wang, J. Zhou, B. Xin, Y. Yu, S. Ren, Z. Li, Phase transformation and tribological properties of Ag-MoO3 contained NiCrAlY based composite coatings fabricated by laser cladding, Opt. Laser Technol. 93 (2017) 79-86. https://doi.org/10.1016/j.optlastec.2017.02.006.

69. [69] J. Bergholz, B.A. Pint, K.A. Unocic, R. Vaßen, Fabrication of Oxide Dispersion Strengthened Bond Coats with Low Al2O3 Content, J. Therm. Spray Technol. 26 (2017) 868-879. https://doi.org/10.1007/s11666-017-0550-9.

70. [70] G. Bolelli, A. Candeli, L. Lusvarghi, A. Ravaux, K. Cazes, A. Denoirjean, S. Valette, C. Chazelas, E. Meillot, L. Bianchi, Tribology of NiCrAlY+Al2O3 composite coatings by plasma spraying with hybrid feeding of dry powder+suspension, Wear. 344-345 (2015) 69-85. https://doi.org/10.1016/j.wear.2015.10.014.

71. [71] F. Ghadami, A. Sabour Rouh Aghdam, A. Zakeri, B. Saeedi, P. Tahvili, Synergistic effect of CeO2 and Al2O3 nanoparticle dispersion on the oxidation behavior of MCrAlY coatings deposited by HVOF, Ceram. Int. 46 (2020) $4556-4567$. https://doi.org/10.1016/j.ceramint.2019.10.184.

72. [72] F. Ghadami, A. Zakeri, A.S.R. Aghdam, R. Tahmasebi, Structural characteristics and high-temperature oxidation behavior of HVOF sprayed nano-CeO2 reinforced NiCoCrAlY nanocomposite coatings, Surf. Coatings Technol. 373 (2019) 7-16. https://doi.org/10.1016/j.surfcoat.2019.05.062.

73. [73] G. Bolelli, A. Candeli, L. Lusvarghi, T. Manfredini, A. Denoirjean, S. Valette, A. Ravaux, E. Meillot, “Hybrid” plasma spraying of NiCrAlY+Al2O3+h-BN composite coatings for sliding wear applications, Wear. 378-379 (2017) 68-81. https://doi.org/10.1016/j.wear.2017.02.027.

74. [74] H.S. Nithin, V. Desai, M.R. Ramesh, Elevated Temperature Solid Particle Erosion Performance of Plasma-Sprayed Cobased Composite Coatings with Additions of Al2O3 and CeO2, J. Mater. Eng. Perform. 26 (2017) 5251-5261. https://doi.org/10.1007/s11665-017-2973-3.

75. [75] M. Bai, B. Song, L. Reddy, T. Hussain, Preparation of MCrAlY-Al2O3 Composite Coatings with Enhanced Oxidation Resistance through a Novel Powder Manufacturing Process, J. Therm. Spray Technol. 28 (2019) 433-443. https://doi.org/10.1007/s11666-019-00830-y.

76. [76] Y.N. Wu, G. Zhang, Z.C. Feng, B.C. Zhang, Y. Liang, F.J. Liu, Oxidation behavior of laser remelted plasma sprayed NiCrAlY and NiCrAlY-Al2O3 coatings, Surf. Coatings Technol. 138 (2001) 56-60. https://doi.org/10.1016/S0257-8972(00)011026.

77. [77] Gurmail Singh, N. Bala, V. Chawla, Oxidation Behaviour of HVOF Sprayed NiCrAlY and NiCrAlY-20SiC Coatings on T-91 Boiler Tube Steel, Prot. Met. Phys. Chem. Surfaces. 56 (2020) 134-150. https://doi.org/10.1134/S2070205120010220.

78. [78] G. Singh, N. Bala, V. Chawla, High temperature oxidation behaviour and characterization of NiCrAlY-B4C coatings deposited by HVOF, Mater. Res. Express. 6 (2019) 86436. https://doi.org/10.1088/2053-1591/ab1f96.

79. [79] W. Dongsheng, T. Zongjun, Y. Bin, S. Lida, Preparation and characterization of nano-SiC p strengthened MCrAlY graded coating by laser multi-layer cladding, in: Adv. Mater. Res., Trans Tech Publ, 2012: pp. $1937-1940$. https://doi.org/10.4028/www.scientific.net/AMR.557-559.1937.

80. [80] T. Zhang, C. Huang, H. Lan, L. Du, W. Zhang, Oxidation and Hot Corrosion Behavior of Plasma-Sprayed MCrAlYCr2O3 Coatings, J. Therm. Spray Technol. 25 (2016) 1208-1216. https://doi.org/10.1007/s11666-016-0433-5.

81. [81] N. Jegadeeswaran, K. Udaya Bhat, M.R. Ramesh, Improving Hot Corrosion Resistance of Cobalt Based Superalloy (Superco-605) Using HVOF Sprayed Oxide Alloy Powder Coating, Trans. Indian Inst. Met. 68 (2015) $309-316$. https://doi.org/10.1007/s12666-015-0605-x.

82. [82] K. Bobzin, T. Schläfer, K. Richardt, M. Brühl, Development of oxide dispersion strengthened MCrAlY coatings, in: J. Therm. Spray Technol., 2008: pp. 853-857. https://doi.org/10.1007/s11666-008-9244-7.

83. [83] H.S. Nithin, D. Vijay, M.R. Ramesh, Cyclic Oxidation and Hot Corrosion Behavior of Plasma-Sprayed CoCrAlY + WCCo Coating on Turbine Alloys, J. Fail. Anal. Prev. 18 (2018) 1133-1142. https://doi.org/10.1007/s11668-018-0499-0.

84. [84] M. Okada, R. Vaßen, M. Karger, D. Sebold, D.E. Mack, M.O. Jarligo, F. Bozza, Deposition and oxidation of oxide-dispersed CoNiCrAlY Bondcoats, Proc. Int. Therm. Spray Conf. 23 (2013) 16-21.

85. [85] Q. An, L. Huang, S. Wei, R. Zhang, X. Rong, Y. Wang, L. Geng, Enhanced interfacial bonding and superior oxidation resistance of CoCrAlY-TiB2 composite coating fabricated by air plasma spraying, Corros. Sci. 158 (2019) 108102. https://doi.org/10.1016/j.corsci.2019.108102.

86. [86] T. Wang, J. Liu, L. Qin, J. Tang, J. Wu, Laser Direct Deposition of CoCrAlSiY/YSZ Composites: Densification, Microstructure and Mechanical Properties, J. Therm. Spray Technol. 28 (2019) 862-879. https://doi.org/10.1007/s11666-019-00859-z. 
87. [87] Z. Wei, Y. Wu, S. Hong, W. Yang, W. Shi, Effects of temperature on wear properties and mechanisms of HVOF sprayed cocralyta-10\%al2 o3 coatings and h13 steel, Metals (Basel). 9 (2019) 1224. https://doi.org/10.3390/met9111224.

88. [88] L. Hu, X. Song, X. Zhao, F. Guo, F. Yang, P. Xiao, A robust, hydrophobic CeO2/NiCoCrAlY composite coating with excellent thermal stability and corrosion resistance prepared by air plasma spray, J. Alloys Compd. 861 (2021) 158623. https://doi.org/10.1016/j.jallcom.2021.158623.

89. [89] Y. Xie, Y. Yang, M. Wang, J. Hou, MCrAlY/TaC metal matrix composite coatings produced by electrospark deposition, Acta Metall. Sin. (English Lett. 26 (2013) 173-176. https://doi.org/10.1007/s40195-012-0236-8.

90. [90] X. He, X. Yuan, H. Xu, P. Song, X. Yu, C. Li, T. Huang, Q. Li, K. Lü, J. Feng, J. Lü, J. Lu, Analysis of structure and microhardness of $\mathrm{Al} 2 \mathrm{O} 3-40 \mathrm{wt} . \% \mathrm{TiO} / \mathrm{NiCoCrAl}$ gradient coating with in-situ needle-like phase reinforcement after high-temperature treatment, Ceram. Int. 45 (2019) 14546-14554. https://doi.org/10.1016/j.ceramint.2019.04.171.

91. [91] E. Hao, X. Zhao, Y. An, W. Deng, Y. Ren, H. Zhou, J. Chen, WC-Co reinforced NiCoCrAlYTa composite coating: Effect of the proportion on microstructure and tribological properties, Int. J. Refract. Met. Hard Mater. 84 (2019) 104978. https://doi.org/10.1016/j.ijrmhm.2019.104978.

92. [92] L. Jiaxing, X. Jie, K. Dejun, Microstructure and friction-wear performances of laser-cladded nano-CeO2-reinforced NiCoCrAlY coatings at high temperature, Proc. Inst. Mech. Eng. Part B J. Eng. Manuf. 234 (2020) $1695-1706$. https://doi.org/10.1177/0954405420937533.

93. [93] Houdková, Z. Česánek, E. Smazalová, The high temperature wear and oxidation behavior of CrC-based HVOF coatings, Proc. Int. Therm. Spray Conf. 2 (2017) 600-605.

94. [94] W. Guo, H. Zhang, S. Zhao, Z. Ding, B. Liu, W. Li, H. Xu, H. Liu, Corrosion behavior of the conicraly-al2o3 composite coating based on core-shell structured powder design, Materials (Basel). 14 (2021) 7093. https://doi.org/10.3390/ma14227093.

95. [95] Z. Yi, C. Song, G. Zhang, T. Tong, G. Ma, D. Wu, Microstructure and wear property of zro2-added nicraly prepared by ultrasonic-assisted direct laser deposition, Materials (Basel). 14 (2021) 5785. https://doi.org/10.3390/ma14195785.

96. [96] X. Sun, S. Chen, Y. Wang, Z. Pan, L. Wang, Mechanical properties and thermal shock resistance of HVOF sprayed NiCrAlY coatings without and with nano ceria, J. Therm. Spray Technol. 21 (2012) 818-824. https://doi.org/10.1007/s11666-0129760-3.

97. [97] H.Y. Wang, D.W. Zuo, X.F. Li, M.D. Wang, Y.F. Zhao, Effects of nano-Al $2 \mathrm{O} 3 p$ on high temperature frictional wear behaviors of NiCoCrAlY cladded coatings, in: Adv. Mater. Res., Trans Tech Publ, 2012: pp. 40-43. https://doi.org/10.4028/www.scientific.net/AMR.426.40.

98. [98] S.C. Tjong, Novel nanoparticle-reinforced metal matrix composites with enhanced mechanical properties, Adv. Eng. Mater. 9 (2007) 639-652.

99. [99] V. Matikainen, H. Koivuluoto, P. Vuoristo, A study of Cr3C2-based HVOF- and HVAF-sprayed coatings: Abrasion, dry particle erosion and cavitation erosion resistance, Wear. 446-447 (2020) 203188. https://doi.org/10.1016/j.wear.2020.203188.

100. [100] R. Casati, M. Vedani, Metal matrix composites reinforced by Nano-Particles-A review, Metals (Basel). 4 (2014) 65-83. https://doi.org/10.3390/met4010065.

101. [101] N. Ashgriz, Handbook of Atomization and Sprays, Springer Science \& Business Media, 2011. https://doi.org/10.1007/978-1-4419-7264-4.

102. [102] W. Fu, Q. Chen, M. Xu, D. Du, Y. Zou, Y. Zhan, B. Zheng, Microstructure and mechanical properties of plasma sprayed WC-Ni coatings, Jinshu Rechuli/Heat Treat. Met. 44 (2019) 211-215. https://doi.org/10.13251/j.issn.0254-6051.2019.04.043.

103. [103] A. Zakeri, P. Tahvili, E. Bahmani, A. Sabour Rouh Aghdam, Effect of powder manufacturing process on characteristics of nanostructured MCrAlY coatings: dry vs. wet ball milling, J. Compos. Compd. 2 (2021) 9-17. https://doi.org/10.52547/jcc.3.1.2.

104. [104] A. Zakeri, E. Bahmani, A. Sabour Rouh Aghdam, B. Saeedi, A comparative study on the microstructure evolution of conventional and nanostructured MCrAlY powders at high-temperature, Surf. Coatings Technol. 389 (2020) 125629. https://doi.org/10.1016/j.surfcoat.2020.125629.

105. [105] C. Kaplin, M. Brochu, The effect of grain size on the oxidation of NiCoCrAlY, in: Appl. Surf. Sci., 2014: pp. 258-263. https://doi.org/10.1016/j.apsusc.2014.02.056.

106. [106] Z. Khodsiani, H. Mansuri, T. Mirian, The effect of cryomilling on the morphology and particle size distribution of the NiCoCrAlYSi powders with and without nano-sized alumina, Powder Technol. 245 (2013) 7-12. https://doi.org/10.1016/j.powtec.2013.04.010.

107. [107] M. Tahari, M. Shamanian, M. Salehi, Microstructural and morphological evaluation of MCrAlY/YSZ composite produced by mechanical alloying method, J. Alloys Compd. 525 (2012) 44-52. https://doi.org/10.1016/j.jallcom.2012.01.161.

108. [108] S. Todde, R. Licheri, R. Orrù, G. Cao, Spark plasma sintering processing for the evaluation of cryomilled CoNiCrAlY alloys for high temperature applications in oxidizing environment, Chem. Eng. J. $200-202$ (2012) 68-80. https://doi.org/10.1016/j.cej.2012.06.009.

109. [109] C. Suryanarayana, Mechanical alloying and milling, Prog. Mater. Sci. 46 (2001) 1-184. https://doi.org/10.1016/S00796425(99)00010-9.

110. [110] C.U. Hardwicke, Y.C. Lau, Advances in thermal spray coatings for gas turbines and energy generation: A review, J. Therm. Spray Technol. 22 (2013) 564-576. https://doi.org/10.1007/s11666-013-9904-0.

111. [111] P.L. Fauchais, J.V.R. Heberlein, M.I. Boulos, Thermal spray fundamentals: From powder to part, Springer Science \& Business Media, 2014. https://doi.org/10.1007/978-0-387-68991-3.

112. [112] V. V. Sobolev, J.M. Guilemany, J. Nutting, High velocity oxy-fuel spraying: Theory, Structure-Property Relationships and Applications, Maney London, 2004. 
113. [113] H. Singh, B.S. Sidhu, D. Puri, S. Prakash, Use of plasma spray technology for deposition of high temperature oxidation/corrosion resistant coatings - A review, Mater. Corros. 58 (2007) 92-102. https://doi.org/10.1002/maco.200603985.

114. [114] P. Fauchais, A. Vardelle, M. Vardelle, Modelling of plasma spraying of ceramic coatings at atmospheric pressure, Ceram. Int. 17 (1991) 367-379. https://doi.org/10.1016/0272-8842(91)90035-X.

115. [115] P. Fauchais, A. Vardelle, B. Dussoubs, Quo Vadis Thermal Spraying?, Proc. Int. Therm. Spray Conf. 10 (2001) 1-32.

116. [116] P. Fauchais, Understanding plasma spraying, J. Phys. D. Appl. Phys. 37 (2004) R86. https://doi.org/10.1088/00223727/37/9/R02.

117. [117] L. Łatka, L. Pawłowski, M. Winnicki, P. Sokołowski, A. Małachowska, S. Kozerski, Review of functionally graded thermal sprayed coatings, Appl. Sci. 10 (2020) 5153. https://doi.org/10.3390/app10155153.

118. [118] A. Meghwal, A. Anupam, B.S. Murty, C.C. Berndt, R.S. Kottada, A.S.M. Ang, Thermal Spray High-Entropy Alloy Coatings: A Review, J. Therm. Spray Technol. 29 (2020) 857-893. https://doi.org/10.1007/s11666-020-01047-0.

119. [119] K. Korpiola, J.P. Hirvonen, L. Laas, F. Rossi, The influence of nozzle design on HVOF exit gas velocity and coating microstructure, J. Therm. Spray Technol. 6 (1997) 469-474. https://doi.org/10.1007/s11666-997-0033-5.

120. [120] Joshi, Nylen, Advanced Coatings by Thermal Spray Processes, Technologies. 7 (2019) 79. https://doi.org/10.3390/technologies7040079.

121. [121] F. Gärtner, T. Stoltenhoff, T. Schmidt, H. Kreye, The cold spray process and its potential for industrial applications, J. Therm. Spray Technol. 15 (2006) 223-232. https://doi.org/10.1361/105996306X108110.

122. [122] A. Moridi, S.M. Hassani-Gangaraj, M. Guagliano, M. Dao, Cold spray coating: Review of material systems and future perspectives, Surf. Eng. 30 (2014) 369-395. https://doi.org/10.1179/1743294414Y.0000000270.

123. [123] H. Assadi, H. Kreye, F. Gärtner, T. Klassen, Cold spraying - A materials perspective, Acta Mater. 116 (2016) $382-407$. https://doi.org/10.1016/j.actamat.2016.06.034.

124. [124] A. Bonadei, T. Marrocco, Cold sprayed MCrAlY+ X coating for gas turbine blades and vanes, Surf. Coatings Technol. 242 (2014) 200-206.

125. [125] W.R. Chen, E. Irissou, X. Wu, J.-G. Legoux, B.R. Marple, The oxidation behavior of TBC with cold spray CoNiCrAlY bond coat, J. Therm. Spray Technol. 20 (2011) 132-138.

126. [126] A.S. Khanna, W.S. Rathod, Development of CoNiCrAlY oxidation resistant hard coatings using high velocity oxy fuel and cold spray techniques, Int. J. Refract. Met. Hard Mater. 49 (2015) 374-382. https://doi.org/10.1016/j.ijrmhm.2014.08.010.

127. [127] A.C. Karaoglanli, Y. Ozgurluk, K.M. Doleker, Comparison of microstructure and oxidation behavior of CoNiCrAlY coatings produced by APS, SSAPS, D-gun, HVOF and CGDS techniques, Vacuum. 180 (2020) 109609.

128. [128] D. Guo, Y. Wang, R. Fernandez, L. Zhao, B. Jodoin, Cold spray for production of in-situ nanocrystalline MCrAlY coatings-Part I: Process analysis and microstructure characterization, Surf. Coatings Technol. 409 (2021) 126854.

129. [129] D. Guo, L. Zhao, B. Jodoin, Cold Spray for Production of In-Situ Nanocrystalline MCrAlY Coatings - Part II: Isothermal Oxidation Performance, Surf. Coatings Technol. (2021) 126828. https://doi.org/https://doi.org/10.1016/j.surfcoat.2021.126828.

130. [130] F. Gitzhofer, E. Bouyer, M.I. Boulos, Suspension Plasma Spray. U.S. Patent 5,609,921, 26, (1997).

131. [131] Y. Xie, M. Wang, Isothermal oxidation behavior of electrospark deposited MCrAlX-type coatings on a Ni-based superalloy, J. Alloys Compd. 480 (2009) 454-461.

132. [132] D.U. Chang, Laser material processing, SAE Tech. Pap. 56 (1985) 341-388. https://doi.org/10.4271/850406.

133. [133] P. Cavaliere, Laser Cladding of Metals, Laser Cladding Met. (2021). https://doi.org/10.1007/978-3-030-53195-9.

134. [134] A. Yakovlev, P. Bertrand, I. Smurov, Laser cladding of wear resistant metal matrix composite coatings, Thin Solid Films. 453-454 (2004) 133-138. https://doi.org/10.1016/j.tsf.2003.11.085.

135. [135] S. Singh, D.K. Goyal, P. Kumar, A. Bansal, Laser cladding technique for erosive wear applications: A review, Mater. Res. Express. 7 (2020) 12007. https://doi.org/10.1088/2053-1591/ab6894.

136. [136] K. Partes, C. Giolli, F. Borgioli, U. Bardi, T. Seefeld, F. Vollertsen, High temperature behaviour of NiCrAlY coatings made by laser cladding, Surf. Coatings Technol. 202 (2008) 2208-2213. https://doi.org/10.1016/j.surfcoat.2007.09.010.

137. [137] L. Luo, X. Shan, Z. Zou, C. Zhao, X. Wang, A. Zhang, X. Zhao, F. Guo, P. Xiao, A high performance NiCoCrAlY bond coat manufactured using laser powder deposition, Corros. Sci. 126 (2017) 356-365. https://doi.org/10.1016/j.corsci.2017.07.018.

138. [138] J.C. Pereira, J.C. Zambrano, M.J. Tobar, A. Yañez, V. Amigó, High temperature oxidation behavior of laser cladding MCrAlY coatings on austenitic stainless steel, Surf. Coatings Technol. 270 (2015) 243-248. https://doi.org/10.1016/j.surfcoat.2015.02.050.

139. [139] J.C. Pereira, J.C. Zambrano, E. Rayón, A. Yañez, V. Amigó, Mechanical and microstructural characterization of MCrAlY coatings produced by laser cladding: The influence of the Ni, Co and Al content, Surf. Coatings Technol. 338 (2018) 22-31. https://doi.org/10.1016/j.surfcoat.2018.01.073.

140. [140] D. Texier, D. Monceau, Z. Hervier, E. Andrieu, Effect of interdiffusion on mechanical and thermal expansion properties at high temperature of a MCrAlY coated Ni-based superalloy, Surf. Coatings Technol. 307 (2016) 81-90. https://doi.org/10.1016/j.surfcoat.2016.08.059.

141. [141] V. V. Sobolev, J.M. Guilemany, J. Nutting, J.R. Miquel, Development of substrate-coating adhesion in thermal spraying, Int. Mater. Rev. 42 (1997) 117-136. https://doi.org/10.1179/imr.1997.42.3.117.

142. [142] K. Bobzin, M. Öte, T.F. Linke, X. Liao, Influence of process parameter on grit blasting as a pretreatment process for thermal spraying, Proc. Int. Therm. Spray Conf. 1 (2015) 506-512.

143. [143] M. Oksa, E. Turunen, T. Suhonen, T. Varis, S.P. Hannula, Optimization and characterization of high velocity oxy-fuel sprayed coatings: Techniques, materials, and applications, Coatings. 1 (2011) 17-52. https://doi.org/10.3390/coatings1010017. 
144. [144] B. Rajasekaran, G. Mauer, R. Vaßen, Enhanced characteristics of HVOF-sprayed MCrAlY bond coats for TBC applications, J. Therm. Spray Technol. 20 (2011) 1209-1216. https://doi.org/10.1007/s11666-011-9668-3.

145. [145] E. Lugscheider, C. Herbst, L. Zhao, Parameter studies on high-velocity oxy-fuel spraying of MCrAlY coatings, Surf. Coatings Technol. 108-109 (1998) 16-23. https://doi.org/10.1016/S0257-8972(98)00630-6.

146. [146] J.A. Cabral-Miramontes, C. Gaona-Tiburcio, F. Almeraya-Calderón, F.H. Estupiñan-Lopez, G.K. Pedraza-Basulto, C.A. Poblano-Salas, Parameter studies on high-velocity oxy-fuel spraying of CoNiCrAlY coatings used in the aeronautical industry, Int. J. Corros. 2014 (2014). https://doi.org/10.1155/2014/703806.

147. [147] E. Dongmo, M. Wenzelburger, R. Gadow, Analysis and optimization of the HVOF process by combined experimental and numerical approaches, Surf. Coatings Technol. 202 (2008) 4470-4478. https://doi.org/10.1016/j.surfcoat.2008.04.029. [148] M. Li, P.D. Christofides, Modeling and control of high-velocity oxygen-fuel (HVOF) thermal spray: A tutorial review, J. Therm. Spray Technol. 18 (2009) 753-768. https://doi.org/10.1007/s11666-009-9309-2.

149. [149] K. Holmberg, A. Laukkanen, E. Turunen, T. Laitinen, Wear resistance optimisation of composite coatings by computational microstructural modelling, Surf. Coatings Technol. 247 (2014) 1-13. https://doi.org/10.1016/j.surfcoat.2014.02.019.

150. [150] M. Li, P.D. Christofides, Multiscale modeling of HVOF thermal spray process, IFAC Proc. Vol. 16 (2005) $327-332$. https://doi.org/10.3182/20050703-6-cz-1902.01630.

151. [151] M. Li, P.D. Christofides, Computational study of particle in-flight behavior in the HVOF thermal spray process, Chem. Eng. Sci. 61 (2006) 6540-6552. https://doi.org/10.1016/j.ces.2006.05.050.

152. [152] A. Zakeri, E. Bahmani, A.S.R. Aghdam, Impact of MCrAlY feedstock powder modification by high-energy ball milling on the microstructure and high-temperature oxidation performance of HVOF-sprayed coatings, Surf. Coatings Technol. 395 (2020) 125935. https://doi.org/10.1016/j.surfcoat.2020.125935.

153. [153] A. Zakeri, F. Ghadami, A. Sabour Rouhaghdam, B. Saeedi, Study on production of modified MCrAlY powder with nano oxide dispersoids as HVOF thermal spray feedstock using mechanical milling, Mater. Res. Express. 7 (2019) 015030. https://doi.org/10.1088/2053-1591/ab6121.

154. [154] S. Li, C. Langlade, S. Fayeulle, D. Tréheux, Influence of the micro structure of plasma deposited MCrAlY coatings on their tribological behaviour, Surf. Coatings Technol. 100-101 (1998) 7-11. https://doi.org/10.1016/S0257-8972(97)00579-3.

155. [155] T.W. Clyne, S.C. Gill, Residual stresses in thermal spray coatings and their effect on interfacial adhesion: A review of recent work, J. Therm. Spray Technol. 5 (1996) 401-418. https://doi.org/10.1007/BF02645271.

156. [156] Y. He, H. Pang, H. Qi, D. Wang, Z. Li, W. Gao, Micro-crystalline Fe-Cr-Ni-Al-Y2O3 ODS alloy coatings produced by high frequency electric-spark deposition, Mater. Sci. Eng. A. 334 (2002) 179-186. https://doi.org/10.1016/S0921-5093(01)01805-6.

157. [157] S.K. Tang, T.C. Nguyen, Y. Zhou, Materials transfer in electro-spark deposition of TiCp/Ni metal-matrix composite coating on Cu substrate, Weld. J. (Miami, Fla). 89 (2010) 172-180.

158. [158] Y. He, Z. Huang, H. Qi, D. Wang, Z. Li, W. Gao, Oxidation behaviour of micro-crystalline Ni-20Cr-Y2O3 ODS alloy coatings, Mater. Lett. 45 (2000) 79-85. https://doi.org/10.1016/S0167-577X(00)00080-X.

159. [159] Q. Wu, H. Zheng, Z. Zhang, P. Hu, C. Fan, N. Zhong, Y. Liu, High-temperature wear and cyclic oxidation behavior of (Ti, W)C reinforced stainless steel coating deposited by PTA on a plain carbon steel, Surf. Coatings Technol. 425 (2021) 127736. https://doi.org/10.1016/j.surfcoat.2021.127736.

160. [160] S.Z. Chavoshi, S. Xu, A Review on Micro- and Nanoscratching/Tribology at High Temperatures: Instrumentation and Experimentation, J. Mater. Eng. Perform. 27 (2018) 3844-3858. https://doi.org/10.1007/s11665-018-3493-5.

161. [161] W. Steckelmacher, Coatings tribology: Properties, techniques and applications in surface engineering, Elsevier, 1995. https://doi.org/10.1016/0042-207x(95)80062-x.

162. [162] A.S.M. Ang, C.C. Berndt, A review of testing methods for thermal spray coatings, Int. Mater. Rev. 59 (2014) $179-223$. https://doi.org/10.1179/1743280414Y.0000000029.

163. [163] L. Łatka, D. Chicot, A. Cattini, L. Pawłowski, A. Ambroziak, Modeling of elastic modulus and hardness determination by indentation of porous yttria stabilized zirconia coatings, Surf. Coatings Technol. 220 (2013) 131-139. https://doi.org/10.1016/j.surfcoat.2012.07.025.

164. [164] Y. Chen, X. Zhao, M. Bai, L. Yang, C. Li, L. Wang, J.A. Carr, P. Xiao, A mechanistic understanding on rumpling of a NiCoCrAlY bond coat for thermal barrier coating applications, Acta Mater. 128 (2017) 31-42. https://doi.org/10.1016/j.actamat.2017.02.003.

165. [165] H. Waki, T. Kitamura, A. Kobayashi, Effect of thermal treatment on high-temperature mechanical properties enhancement in LPPS, HVOF, and APS CoNiCrAlY coatings, J. Therm. Spray Technol. 18 (2009) 500-509.

166. [166] T. Deng, M.S. Bingley, M.S.A. Bradley, Understanding particle dynamics in erosion testers - A review of influences of particle movement on erosion test conditions, Wear. 267 (2009) 2132-2140.

167. [167] P.H. Shipway, I.M. Hutchings, Measurement of coating durability by solid particle erosion, Surf. Coatings Technol. 71 (1995) 1-8.

168. [168] M. Szala, M. Walczak, A. Świetlicki, Effect of Microstructure and Hardness on Cavitation Erosion and Dry Sliding Wear of HVOF Deposited CoNiCrAlY, NiCoCrAlY and NiCrMoNbTa Coatings, Materials (Basel). 15 (2022) 93.

169. [169] E. Hao, Y. An, X. Zhao, H. Zhou, J. Chen, NiCoCrAlYTa coatings on nickel-base superalloy substrate: Deposition by high velocity oxy-fuel spraying as well as investigation of mechanical properties and wear resistance in relation to heat-treatment duration, Appl. Surf. Sci. 462 (2018) 194-206. https://doi.org/10.1016/j.apsusc.2018.08.111.

170. [170] K. Holmberg, A. Erdemir, Influence of tribology on global energy consumption, costs and emissions, Friction. 5 (2017) 263-284. 
171. [171] R. Jojith, M. Sam, N. Radhika, Recent advances in tribological behavior of functionally graded composites: A review, Eng. Sci. Technol. an Int. J. (2021). https://doi.org/10.1016/j.jestch.2021.05.003.

172. [172] Z. Wei, Y. Wu, W. Yang, S. Hong, L. Qiao, J. Cheng, Effects of loads on high-temperature wear properties of HVOF sprayed CoCrAlYTa-10\%Al2O3 and Cr3C2-NiCr coatings, Mater. Res. Express. 6 (2019) 106541. https://doi.org/10.1088/20531591/ab387f.

173. [173] P.J. Blau, Elevated-temperature tribology of metallic materials, Tribol. Int. 43 (2010) $1203-1208$. https://doi.org/10.1016/j.triboint.2010.01.003.

174. [174] F.H. Stott, High-temperature sliding wear of metals, Tribol. Int. 35 (2002) 489-495. https://doi.org/10.1016/S0301679X(02)00041-5.

175. [175] F.H. Stott, D.S. Lin, G.C. Wood, The structure and mechanism of formation of the "glaze" oxide layers produced on nickel-based alloys during wear at high temperatures, Corros. Sci. 13 (1973) 449-469. https://doi.org/10.1016/0010938X(73)90030-9.

176. [176] D.J. Young, High Temperature Oxidation and Corrosion of Metals: Second Edition, Elsevier, 2016. https://doi.org/10.1016/C2014-0-00259-6.

177. [177] Y. Chen, X. Zhao, P. Xiao, Effect of microstructure on early oxidation of MCrAlY coatings, Acta Mater. 159 (2018) 150162. https://doi.org/10.1016/j.actamat.2018.08.018.

178. [178] J. Shi, T. Zhang, B. Sun, B. Wang, X. Zhang, L. Song, Isothermal oxidation and TGO growth behavior of NiCoCrAlYYSZ thermal barrier coatings on a Ni-based superalloy, J. Alloys Compd. 844 (2020) 156093. https://doi.org/10.1016/j.jallcom.2020.156093.

179. [179] M. Daroonparvar, M.A.M. Yajid, C.M. Kay, H. Bakhsheshi-Rad, R.K. Gupta, N.M. Yusof, H. Ghandvar, A. Arshad, I.S.M. Zulkifli, Effects of Al2O3 diffusion barrier layer (including Y-containing small oxide precipitates) and nanostructured YSZ top coat on the oxidation behavior of HVOF NiCoCrAlTaY/APS YSZ coatings at $1100^{\circ} \mathrm{C}$, Corros. Sci. 144 (2018) 13-34. https://doi.org/10.1016/j.corsci.2018.07.013.

180. [180] M. Roy, Approaches to enhance elevated temperature erosion resistance of Ni-base superalloys, Mater. High Temp. 36 (2019) 142-156. https://doi.org/10.1080/09603409.2018.1482077.

181. [181] E. Bousser, L. Martinu, J.E. Klemberg-Sapieha, Solid particle erosion mechanisms of protective coatings for aerospace applications, Surf. Coatings Technol. 257 (2014) 165-181.

182. [182] M. Demirci, M. Bagci, High temperature solid particle erosion comparison of atmospheric plasma sprayed MCrAlY coatings, Surf. Topogr. Metrol. Prop. 9 (2021) 35007. https://doi.org/10.1088/2051-672X/ac1048.

183. [183] E. Bousser, L. Martinu, J.E. Klemberg-Sapieha, Solid particle erosion mechanisms of hard protective coatings, Surf. Coatings Technol. 235 (2013) 383-393.

184. [184] S.G. Lakshmi, K.T. Swarup, D.K. Das, M. Roy, Erosion behaviour of platinum aluminide bond coat on directionally solidified CM247 and AM1 single crystal superalloys, Surf. Coatings Technol. 429 (2022) 127941. https://doi.org/10.1016/j.surfcoat.2021.127941.

185. [185] R.J.K. Wood, The sand erosion performance of coatings, Mater. Des. 20 (1999) 179-191. https://doi.org/10.1016/s02613069(99)00024-2.

186. [186] S.B. Mishra, S. Prakash, K. Chandra, Studies on erosion behaviour of plasma sprayed coatings on a Ni-based superalloy, Wear. 260 (2006) 422-432. https://doi.org/10.1016/j.wear.2005.02.098.

187. [187] K. Anand Babu, N. Jegadeeswaran, H.S. Nithin, N. Kapilan, Studies on solid particle erosion by HVOF sprayed 25\% (Cr3C2-25 (Ni20Cr)) + 75\% NiCrAlY on Ti-31, Mater. Today Proc. 45 (2020) 246-253. https://doi.org/10.1016/j.matpr.2020.10.431.

188. [188] E.N. Kablov, S.A. Muboyadzhyan, Erosion-resistant coatings for gas turbine engine compressor blades, Russ. Metall. 2017 (2017) 494-504. https://doi.org/10.1134/S0036029517060118.

189. [189] M. Antonov, R. Veinthal, E. Huttunen-Saarivirta, I. Hussainova, A. Vallikivi, M. Lelis, J. Priss, Effect of oxidation on erosive wear behaviour of boiler steels, Tribol. Int. 68 (2013) 35-44. https://doi.org/10.1016/j.triboint.2012.09.011.

190. [190] M. Mathapati, M.R. Ramesh, M. Doddamani, High temperature erosion behavior of plasma sprayed NiCrAlY/WCCo/cenosphere coating, Surf. Coatings Technol. 325 (2017) 98-106. https://doi.org/10.1016/j.surfcoat.2017.06.033.

191. [191] K. Derelizade, A. Rincon, F. Venturi, R.G. Wellman, A. Kholobysov, T. Hussain, High temperature $\left(900^{\circ} \mathrm{C}\right)$ sliding wear of CrNiAlCY coatings deposited by high velocity oxy fuel thermal spray, Surf. Coatings Technol. (2022) 128063.

192. [192] Y. Meng, J. Xu, Z. Jin, B. Prakash, Y. Hu, A review of recent advances in tribology, Friction. 8 (2020) 221-300. https://doi.org/10.1007/s40544-020-0367-2. 